\title{
Review
}

Guideline/Fact Sheet

Diabetes Metab J 2021;45:461-481

https://doi.org/10.4093/dmj.2021.0156

pISSN 2233-6079 · eISSN 2233-6087

DIABET\&S \& METABOLISM JOURNAL

\section{Clinical Practice Guidelines for Diabetes Mellitus in Korea}

\author{
Kyu Yeon Hur ${ }^{1}$, Min Kyong Moon², Jong Suk Park , Soo-Kyung Kim4, Seung-Hwan Lee ${ }^{5}$, Jae-Seung Yun ${ }^{5}$, Jong Ha Baek ${ }^{6}$, \\ Junghyun Noh ${ }^{7}$, Byung-Wan Lee ${ }^{3}$, Tae Jung $\mathrm{Oh}^{8}$, Suk Chon', Ye Seul Yang ${ }^{5}$, Jang Won Son ${ }^{5}$, Jong Han Choi ${ }^{10}$, Kee Ho Song ${ }^{10}$, \\ Nam Hoon Kim ${ }^{11}$, Sang Yong Kim ${ }^{12}$, Jin Wha Kim ${ }^{12}$, Sang Youl Rhee', You-Bin Lee ${ }^{1}$, Sang-Man Jin ${ }^{1}$, Jae Hyeon Kim', \\ Chong Hwa Kim ${ }^{13}$, Dae Jung Kim ${ }^{14}$, SungWan Chun ${ }^{15}$, Eun-Jung Rhee ${ }^{16}$, Hyun Min Kim ${ }^{17}$, Hyun Jung Kim ${ }^{18}$, Donghyun Jee ${ }^{19}$, \\ Jae Hyun Kim ${ }^{20}$, Won Seok Choi ${ }^{21}$, Eun-Young Lee ${ }^{5}$, Kun-Ho Yoon ${ }^{5}$, Seung-Hyun Ko ${ }^{5}$, Committee of Clinical Practice \\ Guidelines, Korean Diabetes Association
}

\begin{abstract}
${ }^{1}$ Division of Endocrinology and Metabolism, Department of Medicine, Samsung Medical Center, Sungkyunkwan University School of Medicine, Seoul, ${ }^{2}$ Department of Internal Medicine, Seoul Metropolitan Government Seoul National University Boramae Medical Center, Seoul National University College of Medicine, Seoul,

${ }^{3}$ Department of Internal Medicine, Yonsei University College of Medicine, Seoul,

${ }^{4}$ Division of Endocrinology and Metabolism, Department of Internal Medicine, CHA Bundang Medical Center, CHA University, Seongnam,

${ }^{5}$ Division of Endocrinology and Metabolism, Department of Internal Medicine, College of Medicine, The Catholic University of Korea, Seoul,

${ }^{6}$ Division of Endocrinology \& Metabolism, Department of Medicine, Gyeongsang National University Changwon Hospital, Gyeongsang National University College of Medicine, Changwon,

${ }^{7}$ Division of Endocrinology and Metabolism, Department of Internal Medicine, Inje University Ilsan Paik Hospital, Inje University College of Medicine, Goyang, ${ }^{8}$ Department of Internal Medicine, Seoul National University Bundang Hospital, Seoul National University College of Medicine, Seongnam,

${ }^{9}$ Department of Endocrinology and Metabolism, Kyung Hee University College of Medicine, Kyung Hee University Hospital, Seoul,

${ }^{10}$ Division of Endocrinology and Metabolism, Konkuk University Medical Center, Konkuk University School of Medicine, Seoul,

${ }^{11}$ Department of Internal Medicine, Korea University College of Medicine, Seoul,

${ }^{12}$ Division of Endocrinology and Metabolism, Department of Internal Medicine, Chosun University College of Medicine, Gwangju,

${ }^{13}$ Division of Endocrinology \& Metabolism, Department of Internal Medicine, Sejong General Hospital, Bucheon,

${ }^{14}$ Department of Endocrinology and Metabolism, Ajou University School of Medicine, Suwon,

${ }^{15}$ Department of Internal Medicine, Soonchunhyang University Cheonan Hospital, Soonchunhyang University College of Medicine, Cheonan,

${ }^{16}$ Division of Endocrinology and Metabolism, Department of Internal Medicine, Kangbuk Samsung Hospital, Sungkyunkwan University School of Medicine, Seoul,

${ }^{17}$ Division of Endocrinology and Metabolism, Department of Internal Medicine, Chung-Ang University College of Medicine, Seoul,

${ }^{18}$ Institute for Evidence-based Medicine, Cochrane Korea, Department of Preventive Medicine, Korea University College of Medicine, Seoul,

${ }^{19}$ Division of Vitreous and Retina, Department of Ophthalmology, St. Vincent's Hospital, College of Medicine, The Catholic University of Korea, Suwon,

${ }^{20}$ Department of Pediatrics, Seoul National University Bundang Hospital, Seoul National University College of Medicine, Seongnam,

${ }^{21}$ Division of Infectious Diseases, Department of Internal Medicine, Korea University College of Medicine, Korea University Ansan Hospital, Ansan, Korea
\end{abstract}

The Committee of Clinical Practice Guidelines of the Korean Diabetes Association (KDA) updated the previous clinical practice guidelines for Korean adults with diabetes and prediabetes and published the seventh edition in May 2021. We performed a comprehensive systematic review of recent clinical trials and evidence that could be applicable in real-world practice and suitable for the Korean population. The guideline is provided for all healthcare providers including physicians, diabetes experts, and certified diabetes educators across the country who manage patients with diabetes or the individuals at the risk of developing diabetes mellitus. The recommendations for screening diabetes and glucose-lowering agents have been revised and updated. New sections for continuous glucose monitoring, insulin pump use, and non-alcoholic fatty liver disease in patients with diabetes mellitus have been added. The KDA recommends active vaccination for coronavirus disease 2019 in patients with diabetes during the pandemic. An abridgement that contains practical information for patient education and systematic management in the clinic was published separately.

Keywords: Diabetes mellitus; Diagnosis; Practice guideline; Therapeutics

Corresponding author: Seung-Hyun Ko (D) https://orcid.org/0000-0003-3703-1479 Division of Endocrinology \& Metabolism, Department of Internal Medicine, St. Vincent's Hospital, College of Medicine, The Catholic University of Korea, 93 Jungbu-daero, Paldal-gu, Suwon 16247, Korea

E-mail: kosh@catholic.ac.kr
This is an Open Access article distributed under the terms of the Creative Commons Attribution Non-Commercial License (https://creativecommons.org/licenses/by-nc/4.0/) which permits unrestricted non-commercial use, distribution, and reproduction in any medium, provided the original work is properly cited. 


\section{INTRODUCTION}

According to data from the Korea National Health and Nutrition Examination Survey, $13.8 \%$ of Korean adults aged $\geq 30$ years had diabetes in 2018 [1]. The prevalence of impaired fasting glucose (IFG) was $26.9 \%$. From 2016 to 2018 , 35\% of patients with diabetes were not diagnosed with diabetes. Moreover, among Koreans with diabetes, 53.2\%, 61.3\%, and 72\% were obese, hypertensive, and had hypercholesterolemia, respectively [1]. Therefore, early detection, prevention, and proper management are important issues for diabetes. As an expert group, the Korean Diabetes Association (KDA) has tried to provide appropriate guidelines for these purposes and has cooperated with the government, stakeholders, and related organizations. As a part of this policy, the Committee of Clinical Practice Guidelines of KDA has regularly updated its practice guidelines [2] and recently published the 7th edition.

In this revised edition, the evidence level was classified into four categories: randomized controlled trials (RCTs), including systematic reviews, meta-analyses, and RCTs; non-randomized controlled studies (NRS); others; and expert opinions. According to the target population, each recommendation was classified as a "general recommendation" or a "limited recommendation" if it can be recommended for most subjects or specific subjects, respectively (Table 1).

The section on "Antihyperglycemic therapy for adult patients with diabetes" describes the general principles of treatment, including both oral and injectable medications, have been up-

Table 1. Definition of evidence level and range of recommendations

\begin{tabular}{ll}
\hline Evidence level & \\
RCT & $\begin{array}{c}\text { Systematic reviews, meta-analyses, randomized } \\
\text { controlled trials }\end{array}$ \\
NRS & $\begin{array}{l}\text { Non-randomized controlled studies } \\
\text { Others }\end{array}$ \\
Cxpert opinion & $\begin{array}{c}\text { Expert opinions from consensus of the Committee } \\
\text { of Clinical Practice Guidelines of the KDA }\end{array}$ \\
Range of recommendation \\
General & If the recommendation could be applied to most \\
& of subjects \\
Limited & If the recommendation could be applied to specif- \\
& ic subjects or in specific conditions
\end{tabular}

RCT, randomized controlled trial; NRS, non-randomized controlled study; KDA, Korean Diabetes Association. dated. Furthermore, new sections on the "Diagnosis, evaluation, and treatment of non-alcoholic fatty liver disease (NAFLD)" and "Continuous glucose monitoring (CGM) and insulin pump use in subjects with diabetes" have been added. Additionally, visual leaflets for practical information, video materials and web-based clinical decision supporting systems were developed at the same time to facilitate the implementation and widespread use of these guidelines [3]. A checklist for the comprehensive management of patients with diabetes is provided in the appendix.

\section{DIAGNOSIS OF DIABETES MELLITUS}

The diagnostic criteria for diabetes are based on fasting plasma glucose (FPG), 2-hour plasma glucose (2h-PG) during a $75 \mathrm{~g}$ oral glucose tolerance test (OGTT), or glycosylated hemoglobin (A1C) value (Table 2) [4]. The A1C test should be performed using a method that is certified by the National Glycohemoglobin Standardization Program and should be standardized or traceable to the Diabetes Control and Complications Trial reference assay [4]. Since 2011, A1C has been included as a diagnostic criterion in the KDA clinical practice guidelines [5].

Prediabetes is defined as an FPG value of 100 to $125 \mathrm{mg} / \mathrm{dL}$ (IFG), a 2h-PG value of 140 to $199 \mathrm{mg} / \mathrm{dL}$ after a $75 \mathrm{~g}$ oral glucose load (impaired glucose tolerance [IGT]), or A1C levels of $5.7 \%$ to $6.4 \%[2,4]$. Specifically, the KDA has classified people with IFG into two stages according to their FPG levels: stage 1 IFG (FPG 100 to $109 \mathrm{mg} / \mathrm{dL}$ or A1C 5.7\% to 6.0\%) and stage 2 IFG (FPG 110 to $125 \mathrm{mg} / \mathrm{dL}$ or A1C 6.1\% to 6.4\%) [6].

Table 2. Diagnostic criteria for diabetes mellitus in Korea

1. A 1 C level $\geq 6.5 \%$ or

2. Fasting plasma glucose of $\geq 126 \mathrm{mg} / \mathrm{dL}$ for $>8$ hours $^{\mathrm{a}}$ or

3. 2 hours plasma glucose of $\geq 200 \mathrm{mg} / \mathrm{dL}$ during $75 \mathrm{~g}$ oral glucose tolerance test ${ }^{\mathrm{a}}$ or

4. Classic symptoms of hyperglycemia (polyuria, polydipsia, unexplained weight loss) with a random plasma glucose of $\geq 200 \mathrm{mg} / \mathrm{dL}$

A1C should be measured in a standardized manner.

A1C, glycosylated hemoglobin.

${ }^{a}$ In the absence of apparent hyperglycemia, require repeated verification on different days but can be confirmed immediately if more than two abnormal results are obtained from the same sample. 


\section{SCREENING AND PREVENTION OF DIABETES}

A screening test for diabetes mellitus should be conducted annually for adults over 40 years of age and adults over 30 years of age with risk factors by using the FPG, A1C, and 2h-PG levels during $75 \mathrm{~g}$ OGTT. For subjects with stage 1 IFG, the KDA had previously recommended annual FPG and A1C monitoring to screen for undiagnosed diabetes in the general population. The Korean Diabetes Prevention Study (KDPS), which is the first randomized controlled clinical trial on the prevention of diabetes in high-risk individuals by using intensive lifestyle modifications, is currently ongoing in Korea $[7,8]$. In the KDPS, 75 g OGTT results were obtained from 1,637 overweight or obese Korean adult participants. Among them, $27.2 \%$ had type 2 diabetes mellitus (T2DM), and 59.3\% had IFG and/or IGT. On the basis of the FPG criteria, $31.4 \%$ and $21.5 \%$ of subjects were classified as having stage 1 IFG and stage 2 IFG, respectively. More importantly, $19.0 \%$ of stage 1 and $43.5 \%$ of stage 2 IFG subjects showed 2h-PG levels in the diabetic range [8]. Therefore, the $75 \mathrm{~g}$ OGTT should be actively considered for Korean adults who are overweight or obese (body mass index $[\mathrm{BMI}] \geq 23.0 \mathrm{~kg} / \mathrm{m}^{2}$ ) with stage 1 IFG (FPG 100 to $109 \mathrm{mg} / \mathrm{dL}$ ) and for all adults with stage 2 IFG independent of BMI for early detection and prompt intervention (Expert opinion, General).

To prevent diabetes in subjects with prediabetes, prompt individualized lifestyle modification and education should be introduced according to their BMI. Pre-diabetic adults with a BMI $<23 \mathrm{~kg} / \mathrm{m}^{2}$ should modify their lifestyle by using medical nutrition and exercise therapies (medium or high-level physical activity for at least 150 minutes per week) (Expert opinion, General). If adults have prediabetes and a BMI $\geq 23 \mathrm{~kg} / \mathrm{m}^{2}$, they should be asked to lose $5 \%$ to $10 \%$ of their body weight and maintain the reduced weight by lifestyle modification with medical nutrition and exercise therapies (RCT, General) [912]. The use of metformin may be considered to prevent the development of T2DM among adults with a BMI $\geq 23 \mathrm{~kg} / \mathrm{m}^{2}$ and aged 30 to 70 years (RCT, Limited) [13]. To maintain lifestyle modification, the patient should be continuously motivated and monitored in various ways, including individualized diabetes education and use of aids based on information and communications technology (Expert opinion, General) [12].

\section{GLYCEMIC, BLOOD PRESSURE, AND LIPID CONTROL TARGETS IN T2DM}

Intensive and strict glycemic control with lifestyle modifications has been emphasized to prevent microvascular and macrovascular diabetic complications in T2DM (RCT, General) [14-16]. Therefore, the long-term maintenance of glycemic control status within the near-normal range is very important for patients with diabetes [17]. The optimal A1C target for patients with T2DM is $<6.5 \%$ via lifestyle modification and glucose-lowering agents (RCT, General) (Table 3), particularly in recently diagnosed, young patients with T2DM without severe complications or hypoglycemia (Expert opinion, General). However, the glycemic target should be individualized on the basis of the patients' clinical characteristics. In patients with a history of severe hypoglycemia, advanced diabetic complications, short life expectancy, or advanced age, the glycemic target must be set by considering the risks of complications, such as hypoglycemia (NRS, General) [18-20].

Blood pressure (BP) should be measured at every clinic visit and at home (NRS, General). For patients with diabetes and BP $>120 / 80 \mathrm{~mm} \mathrm{Hg}$, lifestyle modification should be initiated (RCT, General). The target BP level for patients with diabetes is $<140 \mathrm{~mm} \mathrm{Hg}$ systolic BP and $85 \mathrm{~mm} \mathrm{Hg}$ diastolic BP (RCT, General) [21-25]. The target BP for patients with diabetes and cardiovascular disease (CVD) should be $<130 / 80$ mm Hg (Expert opinion, Limited) [26]. Patients with diabetes and high BP could be prescribed any class of antihypertensive medication as the primary medication for $\mathrm{BP}$ control to achieve the target range (RCT, General). There was no difference on the effect of preventing CVD between angiotensin-converting enzyme

Table 3. Glycemic, blood pressure, and lipid control targets in patients with type 2 diabetes mellitus

\begin{tabular}{lll}
\hline Cardiovascular disease & Present & Absent \\
\hline A1C, \% & $<6.5^{\mathrm{a}}$ & $<6.5^{\mathrm{a}}$ \\
Blood pressure, mm Hg & $<130 / 80$ & $<140 / 85$ \\
LDL-C, mg/dL & $<70$ & $<100^{\mathrm{b}}$ \\
Triglycerides, mg/dL & $<150$ & $<150$ \\
HDL-C, mg/dL & $>40$ (men), $>50$ (women) \\
\hline
\end{tabular}

A1C, glycosylated hemoglobin; LDL-C, low-density lipoprotein cholesterol; HDL-C, high-density lipoprotein cholesterol.

${ }^{a} \mathrm{~A} 1 \mathrm{C}$ target should be individualized according to the patient's clinical condition, ${ }^{b}$ Target LDL-C is also $<70 \mathrm{mg} / \mathrm{dL}$ in the presence of target organ damage or cardiovascular risk factors. 
(ACE) inhibitors, angiotensin II receptor blockers (ARBs), calcium channel blockers, and beta-blockers, which can all be used as first-line antihypertensive agents in patients with T2DM $[27,28]$. If BP is not controlled by the initial antihypertensive medication, combination therapy using drugs with different mechanisms is recommended. However, the combination of ACE inhibitors and ARBs is not recommended (RCT, General). Patients with coronary artery disease and diabetes are advised to use ACE inhibitors or ARBs as a first-line therapy (RCT, General) [29]. ACE inhibitors or ARBs are also recommended when high $\mathrm{BP}$ is accompanied by albuminuria (NRS, General) [30-32].

To assess the risk of CVD, a serum lipid test, which measures total cholesterol, high-density lipoprotein cholesterol, triglycerides, and low-density lipoprotein cholesterol (LDL-C), should be performed at least once a year when diagnosing diabetes (Expert opinion, General). LDL-C concentration was graded according to risk level. Patients with diabetes and CVD are classified as very high risk, and LDL-C targets should be adjusted to $<70 \mathrm{mg} / \mathrm{dL}$ (RCT, General) $[33,34]$. In individuals with diabetes who also have target organ damage (albuminuria or estimated glomerular filtration rate [eGFR] $<60 \mathrm{~mL} /$ $\mathrm{min} / 1.73 \mathrm{~m}^{2}$ ) or risk factors for CVD (hypertension, smoking, or family history of premature atherosclerotic CVD), an LDLC target of $<70 \mathrm{mg} / \mathrm{dL}$ should be considered (RCT, General) [35]. In patients with diabetes but without CVD, the recommended target for LDL-C is $<100 \mathrm{mg} / \mathrm{dL}$ (RCT, General).

The primary drug of choice for the treatment of dyslipidemia is statins; however, if target lipid levels are not reached even with the maximum tolerated dose of statins, the addition of ezetimibe could be considered (RCT, General) [36-39]. For patients with CVD, a combination of statins and proprotein convertase subtilisin/kexin type 9 inhibitors is recommended if the LDL-C target has not been reached even after adding ezetimibe to the maximally tolerated doses of statins (RCT, Limited) [40,41]. For severe hypertriglyceridemia (>500 mg/ $\mathrm{dL}$ ), treatment with fenofibrate or omega-3 could be considered in the evaluation of secondary causes (NRS, General) [42]. Serum lipid tests need to be performed 4 to 12 weeks after the initiation of lipid-lowering therapy to evaluate the drug response and patient compliance (Expert opinion, General).

\section{OBESITY MANAGEMENT IN T2DM}

According to the 2020 Korean Society for the Study of Obesity
Guidelines, the classification of obesity into classes I, II, and III relies on adult BMI and the World Health Organization guidelines for the Asia-Pacific region. Classes I and II obesity are defined as BMIs of 25.0 to $29.9 \mathrm{~kg} / \mathrm{m}^{2}$ and 30.0 to $34.9 \mathrm{~kg} / \mathrm{m}^{2}$, respectively; class III obesity was newly defined in 2018 as a BMI $\geq 35 \mathrm{~kg} / \mathrm{m}^{2}$ [43].

Obese adults with T2DM should lose at least 5\% of their body weight via lifestyle modifications and maintain their reduced weight (RCT, General) [44,45]. If patients with T2DM and BMI $\geq 25 \mathrm{~kg} / \mathrm{m}^{2}$ (class I) fail to lose weight with diet, physical activity, and behavior counseling, anti-obesity medications can be considered (Others, Limited) [46-48]. If the use of antiobesity drugs does not result in a loss of more than $5 \%$ of body weight within 3 months, it is judged that the effect of the drug is not significant, and changing or discontinuing the drug should be considered (RCT, General). Bariatric surgery can be considered in patients with T2DM with a BMI $\geq 35 \mathrm{~kg} / \mathrm{m}^{2}$ (class III obesity). Bariatric surgery may also be considered in patients with $\mathrm{T} 2 \mathrm{DM}$ with $\mathrm{BMI} \geq 30 \mathrm{~kg} / \mathrm{m}^{2}$ (class II obesity) if nonsurgical treatment fails to lose weight or control glycemia (Table 4) [49,50]. Multidisciplinary care is needed before and after surgery to enhance the effectiveness and safety of bariatric surgery (Expert opinion, General).

\section{ANTIHYPERGLYCEMIC THERAPY FOR ADULT PATIENTS WITH TYPE 1 DIABETES MELLITUS}

The recommended glycemic target for patients with type 1 diabetes mellitus (T1DM) is an A1C $<7.0 \%$ (RCT, General). All patients with T1DM should be systematically trained to adjust their insulin dose so that they can have flexible meals (RCT, General) [51-54]. The level of understanding following education and performance among patients with T1DM should be evaluated, and patients should receive regular feedback following a diagnosis of diabetes (Expert opinion, General). In addition, individualized self-management education should be provided upon diagnosis not only to patients with T1DM but also to parents/caregivers, and regular reassessment should be performed according to the patient's growth and independent development of self-management (Expert opinion, Limited). In particular, patients with T1DM who develop hypoglycemia unawareness or severe hypoglycemia should receive specialized and professional education to prevent hypoglycemia and restore cognitive abilities in case of hypoglycemia (RCT, Limited) [55]. 
Table 4. Classification of obesity and treatment of obesity or overweight adults with diabetes

\begin{tabular}{lcccc}
\hline Classification & $\mathrm{BMI}, \mathrm{kg} / \mathrm{m}^{2}$ & Lifestyle therapy & Medical therapy $^{\mathrm{a}}$ & Bariatric surgery $^{\mathrm{b}}$ \\
\hline Normal & $18.5-22.9$ & - & - & - \\
Overweight & $23.0-24.9$ & $\odot$ & - & - \\
Class I obesity & $25.0-29.9$ & $\odot$ & 0 & - \\
Class II obesity & $30.0-34.9$ & $\odot$ & $\odot$ & $\odot$ \\
Class III obesity & $\geq 35.0$ & $\odot$ & $\odot$ & ( \\
\hline
\end{tabular}

Values are presented as range. $\bullet$, be recommended; (อ), be considered. BMI, body mass index.

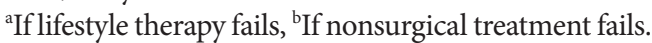

Individuals with T1DM should be treated with intensive insulin replacement using multiple daily injections (MDIs) of prandial and basal insulin or insulin pumps (RCT, General). Rapid-acting insulin analogs (lispro, glulisine, or aspart) and long-acting insulin analogs (glargine, detemir, or degludec) should be used first in patients with T1DM when treated with MDIs (RCT, General) [14,56-61].

\section{ANTIHYPERGLYCEMIC THERAPY FOR ADULT PATIENTS WITH T2DM}

Diabetes education for patients with T2DM is an essential and fundamental part of diabetes management. Certified healthcare professionals should actively educate the patient on lifestyle modification immediately upon diagnosis, and this should be continuously monitored (RCT, General). Following glucose-lowering agent initiation, monotherapy or combination therapy should be provided on the basis of the target and current A1C levels (RCT, General). In general, the glucoselowering efficacy (reduction of A1C) of monotherapy with an oral anti-diabetic drug is estimated to be $1.0 \%$; therefore, if the current $\mathrm{A} 1 \mathrm{C}$ is $1.5 \%$ to $2.0 \%$ higher than that of the target $\mathrm{A} 1 \mathrm{C}$, initial combination therapy is recommended (Figs. 1 and 2) $[15,62]$. However, insulin treatment should be prioritized if severe hyperglycemia (A1C >9.0\%) is accompanied by symptoms of hyperglycemia (polydipsia, polyuria, weight loss, etc.) (Expert opinion, General) (Fig. 3). When choosing a glucoselowering agent, consider whether there are any associated comorbidities (heart failure [HF], established atherosclerotic cardiovascular disease [eASCVD], or chronic kidney disease [CKD]) (Fig. 4) as well as the glucose-lowering efficacy, hypoglycemia risk or weight change, side effects, treatment acceptability, age, personal value of life, and cost (Expert opinion,
General) (Figs. 1 to 3).

Metformin is recommended as a first-line glucose-lowering agent in patients with T2DM and is maintained as long as there are no contraindications or intolerable side effects (RCT, General) (Fig. 1). In the Practical Evidence of Antidiabetic Monotherapy study, the glucose-lowering efficacy of sulfonylureas, metformin, and thiazolidinediones as a monotherapy administered for 48 weeks were similar in drug-naïve Korean patients with T2DM [63]. Metformin has adequate efficacy, low hypoglycemia risk, weight neutrality, and cost-effectiveness. However, if there are contraindications or intolerable side effects related to metformin use, a different class of medications can be considered (Expert opinion, General). If the target A1C level has not been achieved, the up-titration of existing medication, combination therapy using medications with different mechanisms of action, or use of injectable medication should actively be considered as soon as possible; however, dipeptidyl peptidase-4 (DPP-4) inhibitor and glucagon-like peptide 1 receptor agonist (GLP-1RA) should not be combined at the same time (RCT, General) (Fig. 2).

The recent Vildagliptin Efficacy in combination with metfoRmIn for earlY treatment of type 2 diabetes (VERIFY) trial demonstrated that an early intervention strategy with a combination therapy of vildagliptin plus metformin in treatment-naive patients with T2DM provides more durable long-term clinical benefits than metformin monotherapy with a traditional stepwise increase in dosage [64]. According to a subgroup analysis of Korean patients with newly diagnosed T2DM among VERIFY trial participants, early combination treatment significantly and consistently improved long-term glycemic durability compared with monotherapy with metfor$\min$ [65]. Therefore, to reduce the risk of failure of glycemic control, early initial combination therapy is recommended fol- 


\section{Algorithm 1 | Initial therapy}

\section{Comprehensive lifestyle modification (including education and monitoring)}

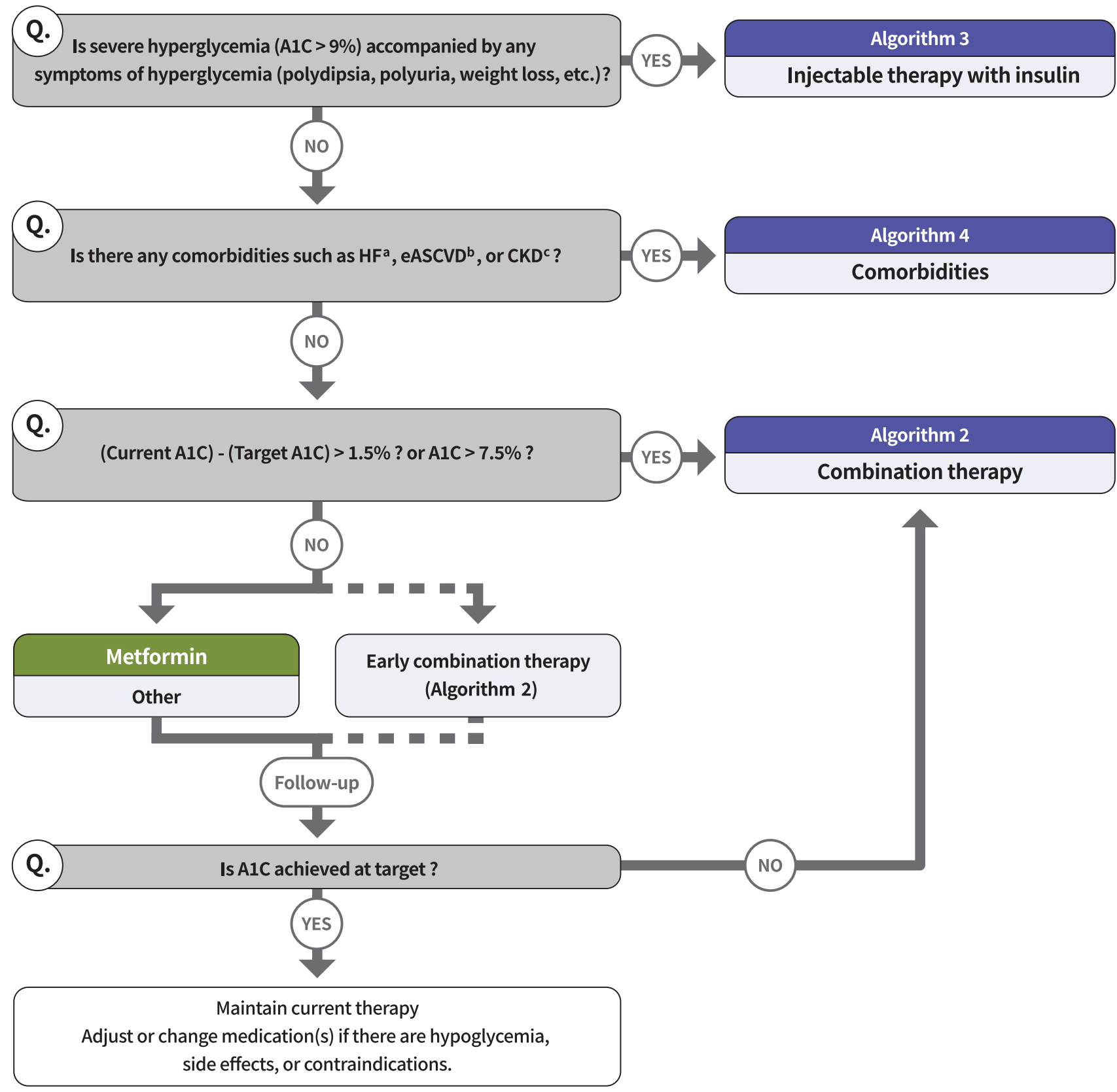

Fig. 1.

(Continued to the next page) 
Fig. 1. Continued. Treatment algorithm 1 (initial therapy) for patients with type 2 diabetes mellitus (T2DM). The algorithm stratifies the strategy of glycemic control for T2DM based on initial glycosylated hemoglobin (A1C) levels and underlying comorbidities. For newly diagnosed T2DM, begin with comprehensive lifestyle modification (LSM) at the time of diagnosis and monitor continuously. If the initial severe hyperglycemia (A1C level $>9.0 \%$ ) is accompanied by symptoms of hyperglycemia (polydipsia, polyuria, weight loss, etc.), insulin treatment should be prioritized (algorithm 3). If heart failure (HF), established atherosclerotic cardiovascular disease (eASCVD), or chronic kidney disease (CKD) are present, follow algorithm 4. If glycemic target is not achieved within 3 months after LSM, then glucose-lowering agent should be initiated promptly. If the current A1C is $1.5 \%$ higher than that of the target $\mathrm{A} 1 \mathrm{C}$ or the current $\mathrm{A} 1 \mathrm{C}$ level is $>7.5 \%$, follow algorithm 2 (combination therapy). If the A1C level is $7.5 \%$ or less, metformin monotherapy is recommended as a first-line therapy. However, if there are contraindications or intolerable side effects related to metformin use, a different class of medications can be considered. Instead of metformin monotherapy, early combination therapy could be considered to reduce the risk of failure of glycemic control in some pa-

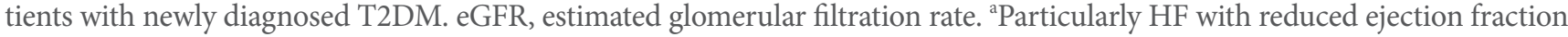
(HFrEF, clinical diagnosis of HF and left ventricular ejection fraction $\leq 40 \%$ ), ${ }^{b} \mathrm{~A}$ history of an acute coronary syndrome or myocardial infarction, stable or unstable angina, coronary heart disease with or without revascularization, other arterial revascularization, stroke, or peripheral artery disease assumed to be atherosclerotic in origin, ${ }^{c} \mathrm{eGFR}<60 \mathrm{~mL} / \mathrm{min} / 1.73 \mathrm{~m}^{2}$ or urine albumin creatinine ratio $\geq 30 \mathrm{mg} / \mathrm{g}$.

lowing the diagnosis of T2DM (RCT, Limited) (Fig. 1).

There is a strong correlation between adherence to glucoselowering agents and metabolic control in T2DM. For each 10\% increment in drug adherence, the A1C level decreases by $0.16 \%$ [66]. Therefore, adherence to medication should be checked regularly, and medication adjustment should not be delayed if necessary (Expert opinion, General).

Injectable therapy (GLP-1RA or insulin) is recommended when potent glucose-lowering efficacy is required (RCT, General) (Fig. 3) [67]. The addition of GLP-1RA, basal insulin, or premixed insulin is recommended equally [68-77]. If A1C target is not achieved with GLP-1RA or basal insulin-based therapy, free or fixed-ratio combination therapy of GLP-1RA and basal insulin could be considered (RCT, Limited) [72,78-94]. Intensification of insulin therapy with premixed insulin twice daily, basal-plus, or basal-bolus is also recommended to enhance blood glucose control (RCT, Limited) [95-99].

Regimens that include sodium-glucose cotransporter 2 (SGLT2) inhibitors or GLP-1RAs with proven cardiovascular (CV) benefits should be prioritized for combination therapy in patients with eASCVD (RCT, Limited) (Fig. 4). T2DM patients with CV risk factors who received empagliflozin treatment had a remarkably lower three-point major adverse cardiovascular event (MACE), including CV death, nonfatal myocardial infarction, and nonfatal stroke, compared with the placebo treatment group (hazard ratio, 0.86 ; 95\% confidence interval, 0.74 to 0.99; EMPA-REG OUTCOME trial) (Table 5) [100]. The effects of empagliflozin on the components of MACE, all-cause mortality, and HF outcomes in Asian patients were also consistent with the overall population of the EMPA-REG study [101].
Dulaglutide [102], liraglutide [103], and semaglutide [104] significantly led to a lower composite three-point MACE outcome compared with the placebo (Table 6).

In patients with T2DM who had or were at risk for atherosclerotic CVD, SGLT2 inhibitor treatment with empagliflozin (EMPEROR-Reduced study), dapagliflozin (DECLARE-TIMI 58 study, DAPA-HF study), and ertugliflozin (VERTIS-CV study) showed lower rates of CV death and hospitalization for HF than placebo treatment regardless of the presence of diabetes [105-107]. For patients with HF, glucose-lowering agents, including SGLT2 inhibitors with proven CV benefits, should be prioritized (RCT, Limited). The use of SGLT2 inhibitors could be beneficial in patients with T2DM suffering from HF symptoms and reduced ejection fraction to reduce the aggravation of $\mathrm{HF}$ and death from CV causes (Table 5).

For patients with albuminuria or reduced eGFR, glucoselowering agents, including SGLT2 inhibitors with proven renal and CV benefits, should be prioritized (RCT, Limited). According to the EMPA-REG OUTCOME trial, empagliflozin treatment led to a significantly lower risk of composite renal outcome (persistent doubling of serum creatinine level, endstage kidney disease [i.e., the need for long-term dialysis or renal transplantation], or death from renal causes) compared with placebo [108]. The DECLARE-TIMI 58 study confirmed that dapagliflozin also led to a lower renal end-point compared with placebo treatment [105]. A recently published DAPACKD study showed that regardless of the presence or absence of diabetes, the risk of renal composite outcomes was significantly lower with dapagliflozin treatment than with placebo in patients with pre-existing CKD (eGFR, 25 to $75 \mathrm{~mL} / \mathrm{min} / 1.73$ 


\section{Algorithm 2 | Combination therapy}

\section{Comprehensive lifestyle modification (including education and monitoring)}

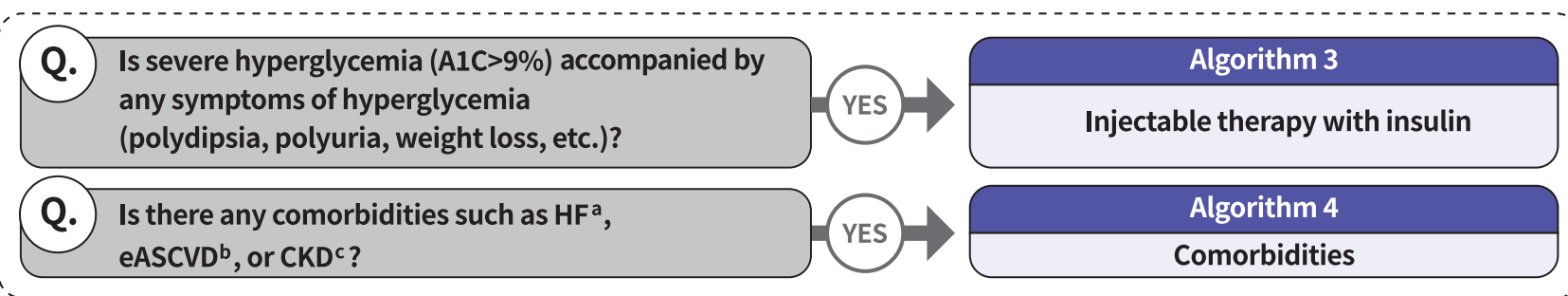

No

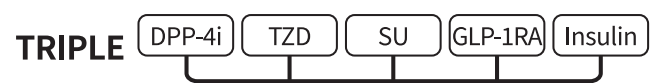

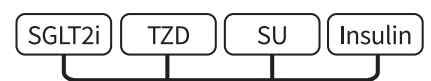

DUAL

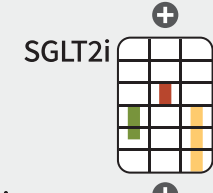

$\oplus$

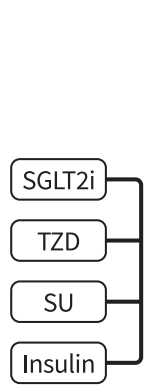

$\oplus$
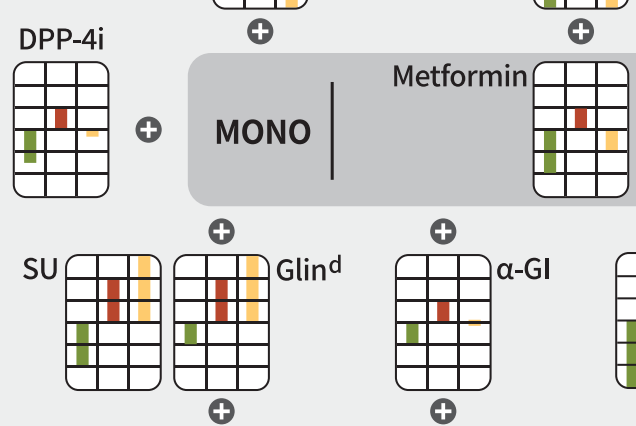

GLP-1RA
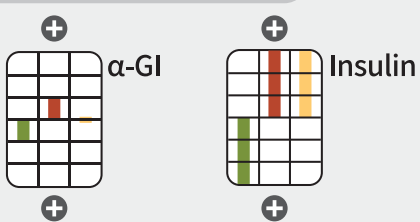

$\oplus$
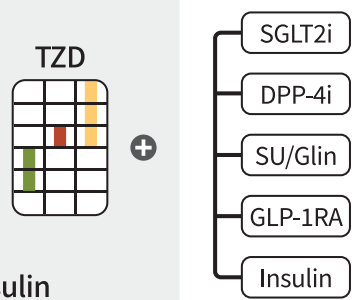

Hypoglycemia

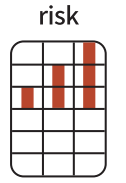

Weight change

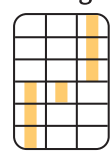

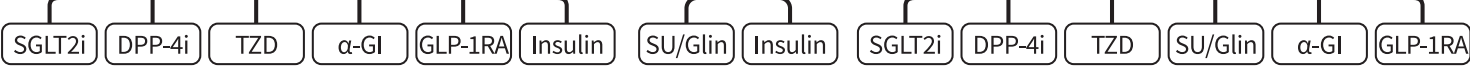

Q.)

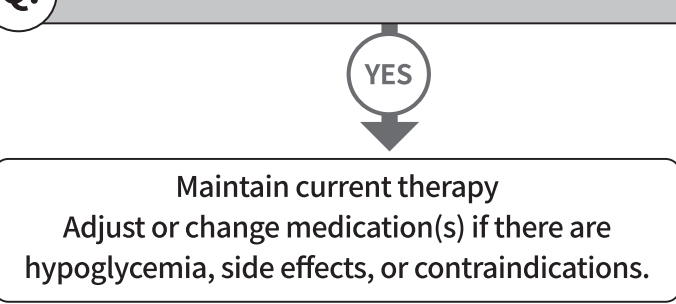

Fig. 2.
Is A1C achieved at target?

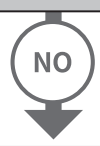

Up-titration of existing medication, combination therapy using drugs with different mechanisms of action (two or more), or injection therapy (Algorithm 3) 
Fig. 2. Continued. Treatment algorithm 2 (combination therapy) for patients with type 2 diabetes mellitus (T2DM). If the current glycosylated hemoglobin $(\mathrm{A} 1 \mathrm{C})$ is $1.5 \%$ higher than that of the target $\mathrm{AlC}$ or the current $\mathrm{A} 1 \mathrm{C}$ level is $>7.5 \%$, combination therapy is recommended. If the target $\mathrm{A} 1 \mathrm{C}$ level has not been achieved, the up-titration of existing medication, combination therapy using medications with different mechanisms of action, or use of injectable medication should actively be considered as soon as possible. When choosing glucose-lowering agents, consider glucose-lowering efficacy, hypoglycemia risk or weight change, side effects, treatment acceptability, age, personal value of life, and cost. The characteristics of glucose-lowering agents are expressed as a bar scale. Each color shows glycemic efficacy (green), hypoglycemia risk (red), and body weight change (yellow). HF, heart failure; eASCVD, established atherosclerotic cardiovascular disease; CKD, chronic kidney disease; eGFR, estimated glomerular filtration rate; DPP-4i, dipeptidyl peptidase-4 inhibitor; TZD, thiazolidinedione; SU, sulfonylurea; GLP-1RA, glucagon-like peptide-1 receptor agonist; SGLT2i, sodium-glucose cotransporter 2 inhibitor; $\alpha$-GI, alpha-glucosidase inhibitor. ${ }^{2}$ Particularly HF with reduced ejection fraction (HFrEF, clinical diagnosis of HF and left ventricular ejection fraction $\leq 40 \%$ ), ${ }^{b}$ History of acute coronary syndrome or myocardial infarction, stable or unstable angina, coronary heart disease with or without revascularization, other arterial revascularization, stroke, or peripheral artery disease assumed to be atherosclerotic in origin, 'eGFR $<60 \mathrm{~mL} /$ $\mathrm{min} / 1.73 \mathrm{~m}^{2}$ or urine albumin creatinine ratio $\geq 30 \mathrm{mg} / \mathrm{g}$, ${ }^{\mathrm{d}}$ Glinide can be used as a dual therapy with metformin, TZD, $\alpha$-GI, or insulin. Glinide can be used as a triple therapy with metformin and $\alpha-G I$, metformin and TZD, or metformin and insulin.

$\mathrm{m}^{2}$; urine albumin-to-creatinine ratio [UACR], 200 to 5,000) [109]. According to recent evidence from large-scale RCTs and meta-analyses, SGLT2 inhibitor treatment in patients with T2DM has proven beneficial effects on renal outcomes, such as progression of albuminuria, aggravation of eGFR, or initiation of renal replacement therapy. Most clinical trials were performed in patients with eASCVD, high risk of CVD, or CKD; therefore, we recommend SGLT2 inhibitors preferentially in these populations.

\section{DIABETIC KIDNEY DISEASE (DIABETIC NEPHROPATHY)}

UACR and eGFR should be evaluated in people with T2DM at the time of diagnosis and at least once a year (NRS, General) [110]. Blood glucose and BP should be controlled optimally to suppress the development and progression of diabetic kidney disease (RCT, General) [24]. Patients with diabetic kidney disease should avoid excessively high or low ( $\leq 0.8 \mathrm{~g} / \mathrm{kg} /$ day $)$ consumption of protein (RCT, General) [111,112]. In patients with diabetes, high BP, and albuminuria, ACE inhibitors or ARBs should be prescribed (RCT, General) [113-115]. The use of ACE inhibitors or ARBs to prevent the progression of diabetic kidney disease is not recommended in patients with normal BP (RCT, General) [116]. Treatment with SGLT2 inhibitors, which have proven $\mathrm{CV}$ and renal benefits, should be prioritized in cases of albuminuria or reduced eGFR (RCT, General) $[105,109,117]$. If the cause of kidney disease is unclear or if renal dysfunction has progressed (GFR $<30 \mathrm{~mL} / \mathrm{min} / 1.73 \mathrm{~m}^{2}$ ), a nephrologist should be consulted (NRS, General).

\section{DIABETIC NEUROPATHY AND FOOT CARE}

Patients with T1DM should be screened 5 years after diagnosis; patients with T2DM should be screened for diabetes-related peripheral and autonomic neuropathy at the time of diagnosis of diabetes and then repeatedly tested every year (RCT, General). Screening tests for diabetic peripheral neuropathy include the Michigan Neuropathy Screening Instrument Questionnaire and a neurological physical examination (Michigan Neuropathy Screening Instrument Examination, a pinching test, and a temperature perception test) (RCT, General) $[118,119]$. In patients with symptoms or signs such as orthostatic hypotension and stable tachycardia, the patient should be tested for CV autonomic neuropathy (RCT, Limited). Strict glycemic control is recommended to prevent or delay the development of peripheral neuropathy and CV autonomic neuropathy in both T1DM and T2DM (RCT, General) [120]. In patients with neuropathic pain, pharmacologic treatment should be used to control the pain and improve the patient's quality of life (RCT, General) [121,122]. Annual comprehensive evaluation to check for risk factors of foot ulcer and amputation and education for foot management should be conducted in adult patients with diabetes (RCT, General) [123]. Peripheral angiography examination should be performed in patients with severe claudication, weak pulse of the dorsalis pedis artery, or ankle brachial index $\leq 0.9$ (Expert opinion, Limited) [124].

\section{DIABETIC RETINOPATHY}

The optimization of blood glucose, BP, and lipid control is rec- 


\section{Algorithm 3 | Injectable therapy}

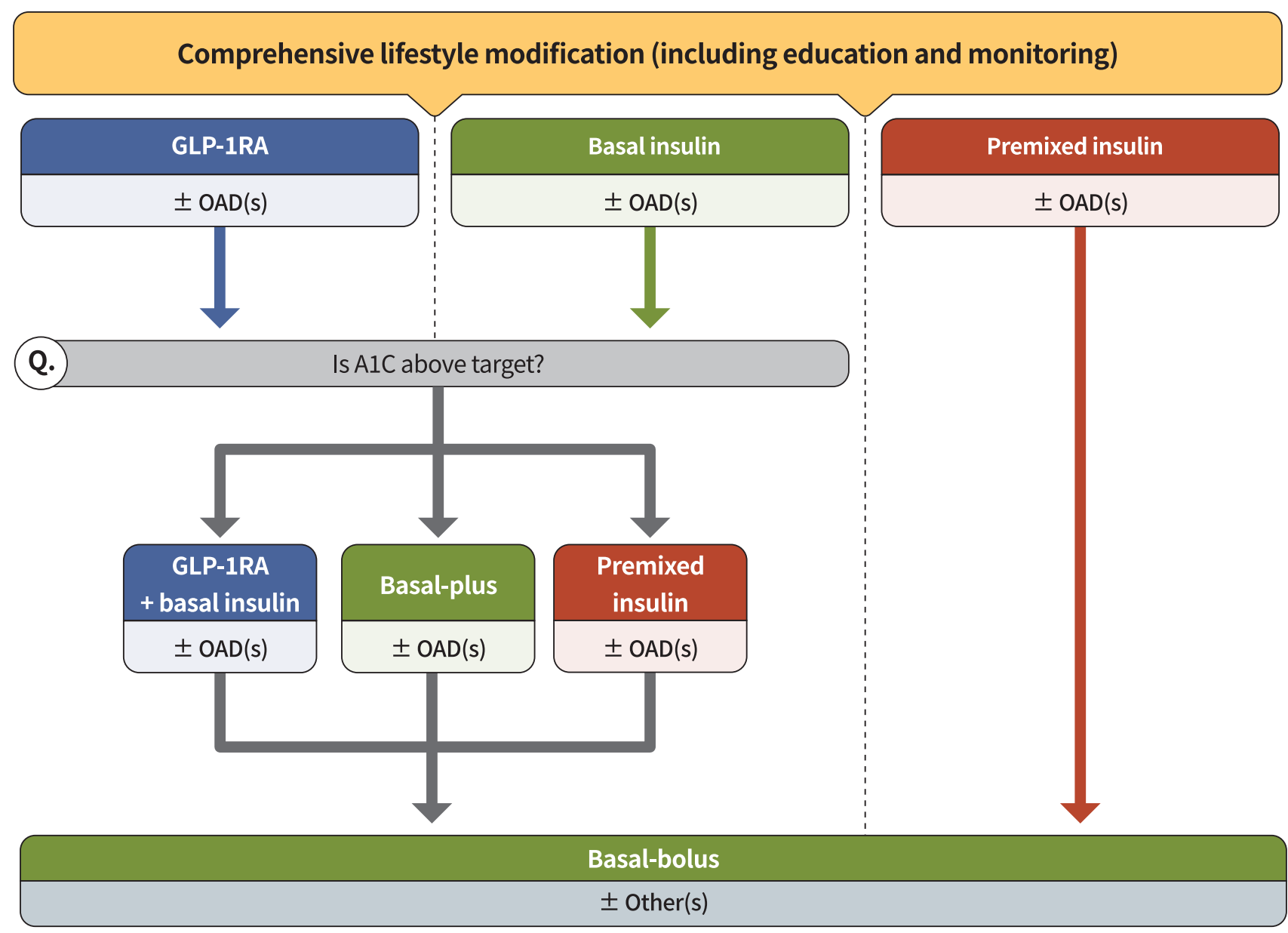

Fig. 3. Treatment algorithm 3 (injectable therapy) for patients with type 2 diabetes mellitus (T2DM). If the glycosylated hemoglobin (A1C) level is $>9.0 \%$ and symptomatic hyperglycemia or metabolic decompensation is present, insulin therapy can be initiated with or without oral anti-diabetic drug (OAD) in patients with T2DM. Injectable therapy (glucagon-like peptide-1 receptor agonist [GLP-1RA] or insulin) is recommended when potent glucose-lowering efficacy is required. The addition of GLP-1RA, basal insulin, or premixed insulin is recommended equally. If A1C target is not achieved with GLP-1RA or basal insulin-based therapy, free or fixed-ratio combination therapy of GLP-1RA and basal insulin could be considered. Intensification of insulin therapy with premixed insulin twice daily, basal-plus, or basal-bolus is also recommended to enhance blood glucose control.

ommended to reduce the risk of developing diabetic retinopathy or to prevent its progression (RCT, General) [15,125]. Patients with T1DM should undergo ophthalmic and comprehensive eye examinations, including the periphery of the retina, within 5 years of diagnosis. Patients with T2DM should undergo ophthalmic and comprehensive eye examinations, including the periphery of the retina, at the time of diagnosis and then every year (Expert opinion, General). If there are no signs of retinopathy and glycemia is well controlled, the patient can be examined at an interval of 1 to 2 years. If a woman with diabetes plans to become pregnant, she must undergo an eye examination in advance; if she becomes pregnant, she should undergo an eye examination within the first 3 months of pregnancy and receive counseling on the development and risk of diabetic retinopathy (RCT, General). The patient should be followed up every 3 months during pregnancy and up to 1 year 


\section{Algorithm 4 | Comorbidities}

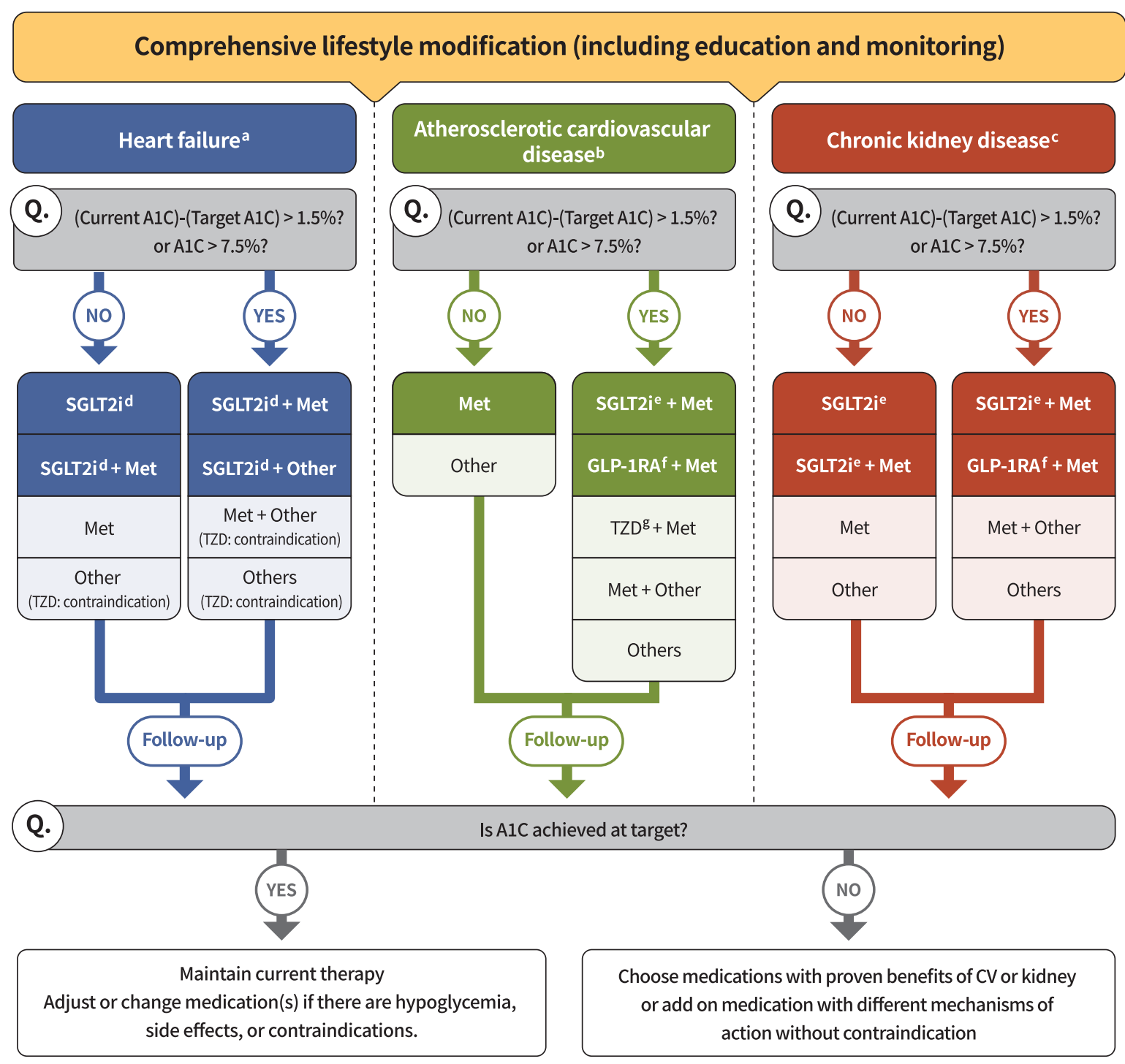

Fig. 4. Treatment algorithm 4 (comorbidities) for patients with type 2 diabetes mellitus who have heart failure (HF), established atherosclerotic cardiovascular disease (eASCVD), or chronic kidney disease (CKD). If patients have underlying above comorbidities, glucose-lowering agents, including sodium-glucose cotransporter 2 (SGLT2) inhibitor or glucagon-like peptide-1 receptor agonist (GLP1-RA), are the preferred choice. For patients with HF, glucose-lowering agents, including SGLT2 inhibitors with proven cardiovascular (CV) benefits, should be prioritized. Regimens that include SGLT2 inhibitors or GLP-1RAs with proven CV benefits should be prioritized for combination therapy in patients with eASCVD. For patients with albuminuria or reduced estimated glomerular filtration rate (eGFR), glucose-lowering agents, including SGLT2 inhibitors with proven renal and CV benefits, should be prioritized. A1C, glycosylated hemoglobin; Met, metformin; TZD, thiazolidinedione. ${ }^{2}$ Particularly HF with reduced ejection frac-

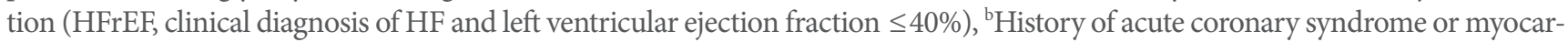
dial infarction, stable or unstable angina, coronary heart disease with or without revascularization, other arterial revascularization, stroke, or peripheral artery disease assumed to be atherosclerotic in origin, ${ }^{c} \mathrm{eGFR}<60 \mathrm{~mL} / \mathrm{min} / 1.73 \mathrm{~m}^{2}$ or urine albumin creatinine ratio $\geq 30 \mathrm{mg} / \mathrm{g}$, ${ }^{\mathrm{d}}$ Dapagliflozin, empagliflozin, ertugliflozin, ${ }^{\mathrm{e}}$ Dapagliflozin, empagliflozin, ${ }^{\mathrm{f} D u l a g l u t i d e}$, liraglutide, semaglutide, ${ }^{\text {PPioglitazone. }}$ 
Table 5. Summary of cardiovascular and renal outcome trials following SGLT2 inhibitor treatment in type 2 diabetes mellitus

\begin{tabular}{|c|c|c|c|c|c|c|}
\hline Variable & $\begin{array}{l}\text { EMPA-REG } \\
\text { OUTCOME }\end{array}$ & $\begin{array}{l}\text { DECLARE- } \\
\text { TIMI } 58\end{array}$ & DAPA-HF & VERTIS-CV & DAPA-CKD & EMPEROR-R \\
\hline No. of patients enrolled & 7,020 & 17,160 & 4,744 & 8,246 & 4,304 & 3,730 \\
\hline Drug & Empagliflozin & Dapagliflozin & Dapagliflozin & Ertugliflozin & Dapagliflozin & Empagliflozin \\
\hline Median follow-up, yr & 3.1 & 4.2 & 1.5 & 3 & 2.4 & 1.3 \\
\hline Mean baseline A1C, \% & 8.1 & 8.3 & NA & 8.2 & NA & NA \\
\hline Mean duration of diabetes, yr & NA & 11 & NA & 13 & NA & NA \\
\hline Baseline statin use, $\%$ & 77 & 75 & NA & 82.3 & 65 & NA \\
\hline Baseline CVD/HF, \% & 99 & 41 & Not reported & 100 & 37 & Not reported \\
\hline Baseline HF, \% & 10 & 10 & 100 & 23.7 & 10.8 & 100 \\
\hline MACE outcome ${ }^{b}$ & $0.86(0.74-0.99)$ & $0.93(0.84-1.03)$ & Not reported & $0.97(0.85-1.11)$ & Not reported & Not reported \\
\hline $\begin{array}{l}\text { Hospitalization for HF or CV } \\
\text { death }\end{array}$ & $0.66(0.55-0.79)$ & $0.83(0.73-0.95)$ & $0.75(0.65-0.85)$ & $0.88(0.75-1.03)$ & $0.71(0.55-0.92)$ & $0.75(0.65-0.86)$ \\
\hline CV death & $0.62(0.49-0.77)$ & $0.98(0.82-1.17)$ & $0.82(0.69-0.98)$ & $0.92(0.77-1.11)$ & $0.81(0.58-1.12)$ & $0.92(0.75-1.12)$ \\
\hline Fatal or nonfatal MI & $0.87(0.70-1.09)$ & $0.89(0.77-1.01)$ & Not reported & $1.04(0.86-1.26)$ & Not reported & Not reported \\
\hline Fatal or nonfatal stroke & $1.18(0.89-1.56)$ & $1.01(0.84-1.21)$ & Not reported & $1.06(0.82-1.37)$ & Not reported & Not reported \\
\hline All-cause mortality & $0.68(0.57-0.82)$ & $0.93(0.82-1.04)$ & $0.83(0.71-0.97)$ & $0.93(0.80-1.08)$ & $0.69(0.53-0.88)$ & $0.92(0.77-1.10)$ \\
\hline HF hospitalization & $0.65(0.50-0.85)$ & $0.73(0.61-0.88)$ & $0.70(0.59-0.83)$ & $0.70(0.54-0.90)$ & Not reported & $0.69(0.59-0.81)$ \\
\hline Renal composite endpoint & $0.54(0.40-0.75)$ & $0.53(0.43-0.66)$ & $0.71(0.44-1.16)$ & $0.81(0.63-1.04)$ & $0.61(0.51-0.72)$ & $0.50(0.32-0.77)$ \\
\hline ESKD & $0.45(0.21-0.97)$ & $0.31(0.13-0.79)$ & $1.00(0.50-1.99)$ & $0.81(0.63-1.04)$ & $0.64(0.50-0.82)$ & Not reported \\
\hline Renal death & Not reported & $0.60(0.22-1.65)$ & NA & NA & NA & Not reported \\
\hline
\end{tabular}

Values are presented as hazard ratio (95\% confidence interval).

SGLT2, sodium-glucose cotransporter 2; A1C, glycosylated hemoglobin; NA, not available; CVD, cardiovascular disease; HF, heart failure; MACE, major adverse cardiovascular events; CV, cardiovascular; MI, myocardial infarction; ESKD, end-stage kidney disease.

${ }^{a} 58.2 \%$ of patients enrolled in DAPA-HF did not have diabetes mellitus. All patients enrolled in DAPA-HF had HF with reduced ejection fraction, ${ }^{b}$ Mean duration of diabetes was not provided for EMPA-REG OUTCOME, but $57 \%$ of patients enrolled had diabetes for more than 10 years.

postpartum [126]. The use of aspirin to prevent CVD does not increase the risk of retinal bleeding (RCT, General) [127]. When the illness progresses to proliferative diabetic retinopathy, panretinal photocoagulation should be performed by a specialist (Expert opinion, General) [128].

\section{NAFLD IN T2DM}

All adults with T2DM should undergo NAFLD evaluation by using alanine aminotransferase or abdominal ultrasonography (Expert opinion, General) [129]. For adults with T2DM and NAFLD, lifestyle modification is required to treat $\mathrm{CV}$ risk factors and fatty liver diseases (RCT, General). Adults with BMI $\geq 23 \mathrm{~kg} / \mathrm{m}^{2}$, NAFLD, and T2DM should lose at least $7 \%$ of their body weight to reduce liver inflammation (RCT, General) [130]. Thiazolidinedione can be used as the initial medication for
NAFLD in adults with T2DM (RCT, Limited) [131]. GLP-1RAs can be used for the treatment of NAFLD in adults with T2DM (RCT, Limited) [132]. Metformin, DPP-4 inhibitors, vitamin E, statins, ursodeoxycholic acid, and pentoxifyline should not be used for the treatment of NAFLD (RCT, General) [133].

\section{CGM SYSTEM AND INSULIN PUMP USE}

CGM results and an ambulatory glucose profile should be analyzed using internationally standardized core metrics (NRS, General) [134]. The clinical benefits of CGM and insulin pump use can only be expected if the patients are trained to use these devices properly and if the information obtained for blood glucose control are properly applied (NRS, General). For adults who treated with MDIs of prandial and basal insulin or insulin pumps, training should be provided professionally and sys- 
Table 6. Summary of the cardiovascular outcome trials following GLP-1 receptor agonist treatment in type 2 diabetes mellitus

\begin{tabular}{|c|c|c|c|}
\hline & REWIND & LEADER & SUSTAIN-6 \\
\hline Patients enrolled & 9,901 & 9,340 & 3,297 \\
\hline Drug & Dulaglutide & Liraglutide & Semaglutide SC \\
\hline Dose & $1.5 \mathrm{mg}$ per week & $1.8 \mathrm{mg}$ or max tolerated dose per day & $0.5 \mathrm{mg}$ or $1 \mathrm{mg}$ per week \\
\hline Median duration of follow-up, yr & 5.4 & 3.8 & 2.1 \\
\hline Mean baseline A1C, \% & 7.2 & 8.7 & 8.7 \\
\hline Mean duration of diabetes, yr & 9.5 & 12.8 & 13.9 \\
\hline Baseline statin use, $\%$ & 66 & 72 & 73 \\
\hline Baseline prevalence of ASCVD/HF, \% & 31 & 81 & 72 \\
\hline Baseline prevalence of HF, \% & 9 & 18 & 24 \\
\hline Primary outcome, 3-MACE ${ }^{\mathrm{a}}$ & $0.88(0.79-0.99)$ & $0.87(0.78-0.97)$ & $0.74(0.58-0.95)$ \\
\hline CV death & $0.91(0.78-1.06)$ & $0.78(0.66-0.93)$ & $0.98(0.65-1.48)$ \\
\hline Fatal or nonfatal $\mathrm{MI}^{\mathrm{b}}$ & $0.96(0.79-1.15)$ & $0.86(0.73-1.00)$ & $0.74(0.51-1.08)$ \\
\hline Fatal or nonfatal stroke ${ }^{b}$ & $0.76(0.62-0.94)$ & $0.86(0.71-1.06)$ & $0.61(0.38-0.99)$ \\
\hline All-cause mortality & $0.90(0.80-1.01)$ & $0.85(0.74-0.97)$ & $1.05(0.74-1.50)$ \\
\hline HF hospitalization $^{c}$ & $0.93(0.77-1.12)^{\mathrm{c}}$ & $0.87(0.73-1.05)$ & $0.86(0.48-1.55)$ \\
\hline Renal composite outcome ${ }^{d}$ & $0.85(0.77-0.93)$ & $0.78(0.67-0.92)$ & $0.64(0.46-0.88)$ \\
\hline
\end{tabular}

Values are presented as hazard ratio (95\% confidence interval).

GLP-1, glucagon-like peptide-1; SC, subcutaneous; A1C, glycosylated hemoglobin; ASCVD, atherosclerotic cardiovascular disease; HF, heart failure; 3-MACE, 3-point major adverse cardiovascular event; CV, cardiovascular; MI, myocardial infarction.

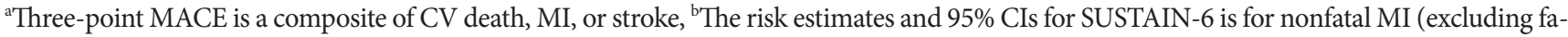
tal MI) or nonfatal stroke (excluding fatal stroke). The effect estimates for the composite endpoints of fatal or nonfatal MI and fatal or nonfatal stroke were not available in the primary manuscripts, ${ }^{\mathrm{C}}$ Urgent $\mathrm{HF}$ visit or hospitalization for HF, ${ }^{\mathrm{d}} \mathrm{The}$ renal composite outcome reported in a recent meta-analysis was a composite of the development of macroalbuminuria, doubling of serum creatinine, a $\geq 40 \%$ decline in estimated glomerular filtration rate (eGFR), development of end-stage kidney disease, or death due to renal causes. For SUSTAIN-6, the renal composite was persistent macroalbuminuria, persistent doubling of serum creatinine with an eGFR $<45 \mathrm{~mL} / \mathrm{min} / 1.73 \mathrm{~m}^{2}$ or need for continuous renal replacement therapy.

tematically (NRS, General). All adult T1DM patients should be encouraged to use real-time CGM devices to control blood glucose and lower the risk of hypoglycemia (RCT, General) [135-137]. Adults with T2DM who require MDIs may use realtime CGM devices for glycemic control (RCT, Limited) [138]. Adults with T2DM who receive treatment other than MDI can periodically perform real-time CGM to control blood glucose (RCT, Limited) [139]. The daily use of real-time CGM devices is recommended for pregnant women with T1DM to control blood glucose, lower the risk of hypoglycemia, and improve perinatal performance (RCT, General) [140].

To reduce the risk of severe hypoglycemia for adult patients with T1DM who experience severe hypoglycemia or hypoglycemia unawareness at least twice a year, insulin pumps rather than MDIs are also recommended even in the absence of CGM (RCT, Limited) [141]. Sensor-enhanced insulin pumps with built-in basal insulin injection interruption algorithms are recommended for adults with T1DM with a high risk of hypoglycemia despite the everyday use of CGM devices (RCT, Limited) [142]. Insulin pumps should only be considered if intensive education is preceded by a professional education system for adults with T2DM whose blood glucose is not controlled by MDIs (RCT, Limited) [143].

\section{VACCINATION FOR PATIENTS WITH T2DM}

An annual flu vaccine is recommended for patients with diabetes. Streptococcus pneumoniae vaccines should also be considered. Coronavirus disease 2019 (COVID-19) vaccination is recommended for patients with diabetes (Expert opinion, General) [144]. 


\section{CONCLUSIONS}

Despite the constant efforts of the KDA, healthcare professionals, and the Korean government, the achievement rates for the comprehensive management of diabetes via $\mathrm{ABC}$ clinical targets (A, A1C <6.5\%; B, BP < 140/85 mm Hg; C, LDL-C < 100 $\mathrm{mg} / \mathrm{dL}$ ) to prevent and delay vascular complications are still low in Korean adult patients with T2DM. Only $11.5 \%$ of subjects achieved all three ABC targets from 2016 to 2018, although there was an increasing trend (9.4\% in 2013-2014, $8.4 \%$ in $2013-2016$, and $11.5 \%$ in $2016-2018$ ) [145]. Patients with diabetes should receive active education from multidisciplinary certified and professional education teams and constant monitoring for adherence to self-management, nutrition, and exercise. To encourage and maintain a properly modified lifestyle, technology-based behavior therapy could be useful. Individualized glycemic target, early and intensive glucose control, clinical strategies to improve adherence to glucoselowering agents and to overcome clinical inertia are necessary to optimize glycemic control in patients with diabetes. In addition, regular check-up and early detection of acute or chronic vascular complications as well as treatment strategies with $\mathrm{CV}$ benefit-proven medications should be considered to reduce comorbidities or mortality in patients with diabetes. The timely updated Clinical Practice Guidelines of KDA will provide evidence-based recommendations to healthcare professionals and contribute the improvement of diabetes care in Korea.

\section{CONFLICTS OF INTEREST}

No potential conflict of interest relevant to this article was reported.

\section{ORCID}

Kyu Yeon Hur https://orcid.org/0000-0002-3065-7252

Seung-Hyun Ko https://orcid.org/0000-0003-3703-1479

\section{FUNDING}

This work was supported by the Korean Diabetes Association.

\section{ACKNOWLEDGMENTS}

We would like to thank the following for their thoughtful peer review and endorsement of the guidelines: the Study group of Neuropathy, Nephropathy, Gestational Diabetes, Beta-cell and islet transplantation, Geriatrics of KDA; Committee of Education, Committee of Food and Nutrition, and Committee of Medical Practitioners of KDA; Korean Association of Internal Medicine; Korean Society of Nephrology; Korean Association of Obesity; Korean Society of Hypertension; Korean Association of Infection; Korean Society of Pediatric Endocrinology; Korean Association of Ophthalmology; Korean Association of Diabetes Dietetic Educators; Korean Association of Diabetes Nurse Educators; and Korean Society of Social Workers for Diabetes Education. We would also like to thank Esther Kim for her contribution to the systematic literature search.

\section{REFERENCES}

1. Jung CH, Son JW, Kang S, Kim WJ, Kim HS, Kim HS, et al. Diabetes fact sheets in Korea, 2020: an appraisal of current status. Diabetes Metab J 2021;45:1-10.

2. Kim MK, Ko SH, Kim BY, Kang ES, Noh J, Kim SK, et al. 2019 Clinical practice guidelines for type 2 diabetes mellitus in Korea. Diabetes Metab J 2019;43:398-406.

3. Korean Diabetes Association: Treatment guideline for diabetes 6th ed. Available from: kdaguideline.com (cited 2021 Jul 16).

4. American Diabetes Association. 2. Classification and diagnosis of diabetes: standards of medical care in diabetes-2018. Diabetes Care 2018;41(Suppl 1):S13-27.

5. Ko SH, Kim SR, Kim DJ, Oh SJ, Lee HJ, Shim KH, et al. 2011 Clinical practice guidelines for type 2 diabetes in Korea. Diabetes Metab J 2011;35:431-6.

6. Oh JY, Lim S, Kim DJ, Kim NH, Kim DJ, Moon SD, et al. A report on the diagnosis of intermediate hyperglycemia in Korea: a pooled analysis of four community-based cohort studies. Diabetes Res Clin Pract 2008;80:463-8.

7. Rhee SY, Chon S, Ahn KJ, Woo JT; Korean Diabetes Prevention Study Investigators. Hospital-based Korean Diabetes Prevention Study: a prospective, multi-center, randomized, openlabel controlled study. Diabetes Metab J 2019;43:49-58.

8. Lee JH, Chon S, Cha SA, Lim SY, Kim KR, Yun JS, et al. Impaired fasting glucose levels in overweight or obese subjects for screening of type 2 diabetes in Korea. Korean J Intern Med 2021;36:382-91.

9. Pan XR, Li GW, Hu YH, Wang JX, Yang WY, An ZX, et al. Effects of diet and exercise in preventing NIDDM in people with 
impaired glucose tolerance: the Da Qing IGT and Diabetes Study. Diabetes Care 1997;20:537-44.

10. Tuomilehto J, Lindstrom J, Eriksson JG, Valle TT, Hamalainen H, Ilanne-Parikka P, et al. Prevention of type 2 diabetes mellitus by changes in lifestyle among subjects with impaired glucose tolerance. N Engl J Med 2001;344:1343-50.

11. Knowler WC, Barrett-Connor E, Fowler SE, Hamman RF, Lachin JM, Walker EA, et al. Reduction in the incidence of type 2 diabetes with lifestyle intervention or metformin. $\mathrm{N}$ Engl J Med 2002;346:393-403.

12. Lee JH, Lim SY, Cha SA, Han CJ, Jung AR, Kim KR, et al. Short-term effects of the Internet-based Korea Diabetes Prevention Study: 6-month results of a community-based randomized controlled trial. Diabetes Metab J 2021 Mar 17 [Epub]. https://doi.org/10.4093/dmj.2020.0225.

13. Ramachandran A, Snehalatha C, Mary S, Mukesh B, Bhaskar $\mathrm{AD}$, Vijay V, et al. The Indian Diabetes Prevention Programme shows that lifestyle modification and metformin prevent type 2 diabetes in Asian Indian subjects with impaired glucose tolerance (IDPP-1). Diabetologia 2006;49:289-97.

14. Diabetes Control and Complications Trial Research Group, Nathan DM, Genuth S, Lachin J, Cleary P, Crofford O, et al. The effect of intensive treatment of diabetes on the development and progression of long-term complications in insulindependent diabetes mellitus. N Engl J Med 1993;329:977-86.

15. UK Prospective Diabetes Study (UKPDS) Group. Intensive blood-glucose control with sulphonylureas or insulin compared with conventional treatment and risk of complications in patients with type 2 diabetes (UKPDS 33). Lancet 1998;352: 837-53.

16. Ohkubo Y, Kishikawa H, Araki E, Miyata T, Isami S, Motoyoshi $\mathrm{S}$, et al. Intensive insulin therapy prevents the progression of diabetic microvascular complications in Japanese patients with non-insulin-dependent diabetes mellitus: a randomized prospective 6-year study. Diabetes Res Clin Pract 1995;28:10317.

17. Holman RR, Paul SK, Bethel MA, Matthews DR, Neil HA. 10Year follow-up of intensive glucose control in type 2 diabetes. N Engl J Med 2008;359:1577-89.

18. Hayward RA, Reaven PD, Wiitala WL, Bahn GD, Reda DJ, Ge $\mathrm{L}$, et al. Follow-up of glycemic control and cardiovascular outcomes in type 2 diabetes. N Engl J Med 2015;372:2197-206.

19. Lee AK, Warren B, Lee CJ, McEvoy JW, Matsushita K, Huang ES, et al. The association of severe hypoglycemia with incident cardiovascular events and mortality in adults with type 2 dia- betes. Diabetes Care 2018;41:104-11.

20. Writing Group for the DCCT/EDIC Research Group, Orchard TJ, Nathan DM, Zinman B, Cleary P, Brillon D, et al. Association between 7 years of intensive treatment of type 1 diabetes and long-term mortality. JAMA 2015;313:45-53.

21. ACCORD Study Group, Cushman WC, Evans GW, Byington RP, Goff DC Jr, Grimm RH Jr, et al. Effects of intensive bloodpressure control in type 2 diabetes mellitus. N Engl J Med 2010;362:1575-85.

22. SPRINT Research Group, Wright JT Jr, Williamson JD, Whelton PK, Snyder JK, Sink KM, et al. A randomized trial of intensive versus standard blood-pressure control. N Engl J Med 2015;373:2103-16.

23. Buckley LF, Dixon DL, Wohlford GF 4th, Wijesinghe DS, Baker WL, Van Tassell BW. Intensive versus standard blood pressure control in SPRINT-eligible participants of ACCORD-BP. Diabetes Care 2017;40:1733-8.

24. UK Prospective Diabetes Study Group. Tight blood pressure control and risk of macrovascular and microvascular complications in type 2 diabetes: UKPDS 38. UK Prospective Diabetes Study Group. BMJ 1998;317:703-13.

25. Hansson L, Zanchetti A, Carruthers SG, Dahlof B, Elmfeldt D, Julius $S$, et al. Effects of intensive blood-pressure lowering and low-dose aspirin in patients with hypertension: principal results of the Hypertension Optimal Treatment (HOT) randomised trial. HOT Study Group. Lancet 1998;351:1755-62.

26. Bakris GL, Gaxiola E, Messerli FH, Mancia G, Erdine S, Cooper-DeHoff R, et al. Clinical outcomes in the diabetes cohort of the INternational VErapamil SR-Trandolapril study. Hypertension 2004;44:637-42.

27. Turnbull F, Neal B, Algert C, Chalmers J, Chapman N, Cutler J, et al. Effects of different blood pressure-lowering regimens on major cardiovascular events in individuals with and without diabetes mellitus: results of prospectively designed overviews of randomized trials. Arch Intern Med 2005;165:1410-9.

28. Bangalore S, Fakheri R, Toklu B, Messerli FH. Diabetes mellitus as a compelling indication for use of renin angiotensin system blockers: systematic review and meta-analysis of randomized trials. BMJ 2016;352:1438.

29. Arnold SV, Bhatt DL, Barsness GW, Beatty AL, Deedwania PC, Inzucchi SE, et al. Clinical management of stable coronary artery disease in patients with type 2 diabetes mellitus: a scientific statement from the American Heart Association. Circulation 2020;141:e779-806.

30. Lindholm LH, Ibsen H, Dahlof B, Devereux RB, Beevers G, de 
Faire U, et al. Cardiovascular morbidity and mortality in patients with diabetes in the Losartan Intervention for Endpoint Reduction in Hypertension Study (LIFE): a randomised trial against atenolol. Lancet 2002;359:1004-10.

31. Berl T, Hunsicker LG, Lewis JB, Pfeffer MA, Porush JG, Rouleau JL, et al. Cardiovascular outcomes in the Irbesartan Diabetic Nephropathy Trial of patients with type 2 diabetes and overt nephropathy. Ann Intern Med 2003;138:542-9.

32. Palmer SC, Mavridis D, Navarese E, Craig JC, Tonelli M, Salanti G, et al. Comparative efficacy and safety of blood pressure-lowering agents in adults with diabetes and kidney disease: a network meta-analysis. Lancet 2015;385:2047-56.

33. Heart Protection Study Collaborative Group. MRC/BHF Heart Protection Study of cholesterol lowering with simvastatin in 20,536 high-risk individuals: a randomised placebocontrolled trial. Lancet 2002;360:7-22.

34. Cholesterol Treatment Trialists' (CTT) Collaboration, Fulcher J, O'Connell R, Voysey M, Emberson J, Blackwell L, et al. Efficacy and safety of LDL-lowering therapy among men and women: meta-analysis of individual data from 174,000 participants in 27 randomised trials. Lancet 2015;385:1397-405.

35. Brugts JJ, Yetgin T, Hoeks SE, Gotto AM, Shepherd J, Westendorp RG, et al. The benefits of statins in people without established cardiovascular disease but with cardiovascular risk factors: meta-analysis of randomised controlled trials. BMJ 2009;338:b2376.

36. Colhoun HM, Betteridge DJ, Durrington PN, Hitman GA, Neil HA, Livingstone SJ, et al. Primary prevention of cardiovascular disease with atorvastatin in type 2 diabetes in the Collaborative Atorvastatin Diabetes Study (CARDS): multicentre randomised placebo-controlled trial. Lancet 2004;364: 685-96.

37. Cholesterol Treatment Trialists' (CTT) Collaborators, Kearney PM, Blackwell L, Collins R, Keech A, Simes J, et al. Efficacy of cholesterol-lowering therapy in 18,686 people with diabetes in 14 randomised trials of statins: a meta-analysis. Lancet 2008;371:117-25.

38. Cannon CP, Blazing MA, Giugliano RP, McCagg A, White JA, Theroux $P$, et al. Ezetimibe added to statin therapy after acute coronary syndromes. N Engl J Med 2015;372:2387-97.

39. Hong N, Lee YH, Tsujita K, Gonzalez JA, Kramer CM, Kovarnik T, et al. Comparison of the effects of ezetimibe-statin combination therapy on major adverse cardiovascular events in patients with and without diabetes: a meta-analysis. Endocrinol Metab (Seoul) 2018;33:219-27.
40. Sabatine MS, Giugliano RP, Keech AC, Honarpour N, Wiviott SD, Murphy SA, et al. Evolocumab and clinical outcomes in patients with cardiovascular disease. N Engl J Med 2017;376: 1713-22.

41. Schwartz GG, Steg PG, Szarek M, Bhatt DL, Bittner VA, Diaz $\mathrm{R}$, et al. Alirocumab and cardiovascular outcomes after acute coronary syndrome. N Engl J Med 2018;379:2097-107.

42. American Diabetes Association. 10. Cardiovascular disease and risk management: standards of medical care in diabetes-2020. Diabetes Care 2020;43(Suppl 1):S111-34.

43. Kim BY, Kang SM, Kang JH, Kang SY, Kim KK, Kim KB, et al. 2020 Korean Society for the Study of Obesity guidelines for the management of obesity in Korea. J Obes Metab Syndr 2021;30:81-92.

44. Look AHEAD Research Group, Wing RR, Bolin P, Brancati FL, Bray GA, Clark JM, et al. Cardiovascular effects of intensive lifestyle intervention in type 2 diabetes. N Engl J Med 2013;369:145-54.

45. Lean ME, Leslie WS, Barnes AC, Brosnahan N, Thom G, McCombie L, et al. Primary care-led weight management for remission of type 2 diabetes (DiRECT): an open-label, clusterrandomised trial. Lancet 2018;391:541-51.

46. Gadde KM, Allison DB, Ryan DH, Peterson CA, Troupin B, Schwiers ML, et al. Effects of low-dose, controlled-release, phentermine plus topiramate combination on weight and associated comorbidities in overweight and obese adults (CONQUER): a randomised, placebo-controlled, phase 3 trial. Lancet 2011;377:1341-52.

47. Davies MJ, Bergenstal R, Bode B, Kushner RF, Lewin A, Skjoth TV, et al. Efficacy of liraglutide for weight loss among patients with type 2 diabetes: the SCALE diabetes randomized clinical trial. JAMA 2015;314:687-99.

48. Hollander P, Gupta AK, Plodkowski R, Greenway F, Bays H, Burns C, et al. Effects of naltrexone sustained-release/bupropion sustained-release combination therapy on body weight and glycemic parameters in overweight and obese patients with type 2 diabetes. Diabetes Care 2013;36:4022-9.

49. Cohen R, Le Roux CW, Junqueira S, Ribeiro RA, Luque A. Roux-en-Y gastric bypass in type 2 diabetes patients with mild obesity: a systematic review and meta-analysis. Obes Surg 2017;27:2733-9.

50. Yeo D, Yeo C, Low TY, Ahmed S, Phua S, Oo AM, et al. Outcomes after metabolic surgery in asians-a meta-analysis. Obes Surg 2019;29:114-26.

51. Bell KJ, Barclay AW, Petocz P, Colagiuri S, Brand-Miller JC. 
Efficacy of carbohydrate counting in type 1 diabetes: a systematic review and meta-analysis. Lancet Diabetes Endocrinol 2014;2:133-40.

52. Rytter K, Schmidt S, Rasmussen LN, Pedersen-Bjergaard U, Norgaard K. Education programmes for persons with type 1 diabetes using an insulin pump: a systematic review. Diabetes Metab Res Rev 2021;37:e3412.

53. DAFNE Study Group. Training in flexible, intensive insulin management to enable dietary freedom in people with type 1 diabetes: dose adjustment for normal eating (DAFNE) randomised controlled trial. BMJ 2002;325:746.

54. Sanchez-Hernandez RM, Alvarado-Martel D, Lopez-Plasencia Y, Carrillo-Dominguez A, Jimenez-Rodriguez A, Rodriguez-Cordero J, et al. Assessment of Alimentacion Normal con Ajuste de Insulina (ANAIS), a Spanish version of the DAFNE programme, in people with type 1 diabetes: a randomized controlled parallel trial. Diabet Med 2019;36:103745.

55. Little SA, Speight J, Leelarathna L, Walkinshaw E, Tan HK, Bowes A, et al. Sustained reduction in severe hypoglycemia in adults with type 1 diabetes complicated by impaired awareness of hypoglycemia: two-year follow-up in the HypoCOMPaSS randomized clinical trial. Diabetes Care 2018;41:1600-7.

56. Nathan DM, Cleary PA, Backlund JY, Genuth SM, Lachin JM, Orchard TJ, et al. Intensive diabetes treatment and cardiovascular disease in patients with type 1 diabetes. $\mathrm{N}$ Engl J Med 2005;353:2643-53.

57. Writing Team for the Diabetes Control and Complications Trial/Epidemiology of Diabetes Interventions and Complications Research Group. Effect of intensive therapy on the microvascular complications of type 1 diabetes mellitus. JAMA 2002;287:2563-9.

58. Chico A, Corcoy R. Intensive insulin therapy ( $\simeq$ Basal-Bolus). Am J Ther 2020 Oct 6 [Epub]. https://doi.org/10.1097/ MJT.0000000000001152.

59. Bergenstal RM, Tamborlane WV, Ahmann A, Buse JB, Dailey G, Davis SN, et al. Effectiveness of sensor-augmented insulinpump therapy in type 1 diabetes. N Engl J Med 2010;363:31120.

60. Laranjeira FO, de Andrade KR, Figueiredo AC, Silva EN, Pereira MG. Long-acting insulin analogues for type 1 diabetes: an overview of systematic reviews and meta-analysis of randomized controlled trials. PLoS One 2018;13:e0194801.

61. Melo KF, Bahia LR, Pasinato B, Porfirio GJ, Martimbianco AL, Riera $\mathrm{R}$, et al. Short-acting insulin analogues versus regular human insulin on postprandial glucose and hypoglycemia in type 1 diabetes mellitus: a systematic review and meta-analysis. Diabetol Metab Syndr 2019;11:2.

62. Holman RR, Thorne KI, Farmer AJ, Davies MJ, Keenan JF, Paul S, et al. Addition of biphasic, prandial, or basal insulin to oral therapy in type 2 diabetes. N Engl J Med 2007;357:171630.

63. Yoon KH, Shin JA, Kwon HS, Lee SH, Min KW, Ahn YB, et al. Comparison of the efficacy of glimepiride, metformin, and rosiglitazone monotherapy in Korean drug-naive type 2 diabetic patients: the practical evidence of antidiabetic monotherapy study. Diabetes Metab J 2011;35:26-33.

64. Matthews DR, Paldanius PM, Proot P, Chiang Y, Stumvoll M, Del Prato S, et al. Glycaemic durability of an early combination therapy with vildagliptin and metformin versus sequential metformin monotherapy in newly diagnosed type 2 diabetes (VERIFY): a 5-year, multicentre, randomised, doubleblind trial. Lancet 2019;394:1519-29.

65. Yoo SJ, Chang SA, Sohn TS, Kwon HS, Lee JM, Moon S, et al. Long-term glycaemic durability of early combination therapy strategy versus metformin monotherapy in Korean patients with newly diagnosed type 2 diabetes mellitus. Diabetes Metab J 2020 Nov 12 [Epub]. https://doi.org/10.4093/dmj.2020.0173.

66. Schectman JM, Nadkarni MM, Voss JD. The association between diabetes metabolic control and drug adherence in an indigent population. Diabetes Care 2002;25:1015-21.

67. Tsapas A, Avgerinos I, Karagiannis T, Malandris K, Manolopoulos A, Andreadis P, et al. Comparative effectiveness of glucose-lowering drugs for type 2 diabetes: a systematic review and network meta-analysis. Ann Intern Med 2020;173:27886.

68. Davies MJ, Donnelly R, Barnett AH, Jones S, Nicolay C, Kilcoyne A. Exenatide compared with long-acting insulin to achieve glycaemic control with minimal weight gain in patients with type 2 diabetes: results of the Helping Evaluate Exenatide in patients with diabetes compared with Long-Acting insulin (HEELA) study. Diabetes Obes Metab 2009;11:115362.

69. Heine RJ, Van Gaal LF, Johns D, Mihm MJ, Widel MH, Brodows RG, et al. Exenatide versus insulin glargine in patients with suboptimally controlled type 2 diabetes: a randomized trial. Ann Intern Med 2005;143:559-69.

70. Russell-Jones D, Vaag A, Schmitz O, Sethi BK, Lalic N, Antic S, et al. Liraglutide vs insulin glargine and placebo in combination with metformin and sulfonylurea therapy in type 2 diabe- 
tes mellitus (LEAD-5 met+SU): a randomised controlled trial. Diabetologia 2009;52:2046-55.

71. D’Alessio D, Haring HU, Charbonnel B, de Pablos-Velasco P, Candelas C, Dain MP, et al. Comparison of insulin glargine and liraglutide added to oral agents in patients with poorly controlled type 2 diabetes. Diabetes Obes Metab 2015;17:1708.

72. Gough SC, Bode B, Woo V, Rodbard HW, Linjawi S, Poulsen P, et al. Efficacy and safety of a fixed-ratio combination of insulin degludec and liraglutide (IDegLira) compared with its components given alone: results of a phase 3, open-label, randomised, 26-week, treat-to-target trial in insulin-naive patients with type 2 diabetes. Lancet Diabetes Endocrinol 2014; 2:885-93.

73. Gough SC, Bode BW, Woo VC, Rodbard HW, Linjawi S, Zacho M, et al. One-year efficacy and safety of a fixed combination of insulin degludec and liraglutide in patients with type 2 diabetes: results of a 26-week extension to a 26-week main trial. Diabetes Obes Metab 2015;17:965-73.

74. Araki E, Inagaki N, Tanizawa Y, Oura T, Takeuchi M, Imaoka T. Efficacy and safety of once-weekly dulaglutide in combination with sulphonylurea and/or biguanide compared with once-daily insulin glargine in Japanese patients with type 2 diabetes: a randomized, open-label, phase III, non-inferiority study. Diabetes Obes Metab 2015;17:994-1002.

75. Blonde L, Jendle J, Gross J, Woo V, Jiang H, Fahrbach JL, et al. Once-weekly dulaglutide versus bedtime insulin glargine, both in combination with prandial insulin lispro, in patients with type 2 diabetes (AWARD-4): a randomised, open-label, phase 3, non-inferiority study. Lancet 2015;385:2057-66.

76. Giorgino F, Benroubi M, Sun JH, Zimmermann AG, Pechtner V. Efficacy and safety of once-weekly dulaglutide versus insulin glargine in patients with type 2 diabetes on metformin and glimepiride (AWARD-2). Diabetes Care 2015;38:2241-9.

77. Aroda VR, Bain SC, Cariou B, Piletic M, Rose L, Axelsen M, et al. Efficacy and safety of once-weekly semaglutide versus once-daily insulin glargine as add-on to metformin (with or without sulfonylureas) in insulin-naive patients with type 2 diabetes (SUSTAIN 4): a randomised, open-label, parallelgroup, multicentre, multinational, phase 3a trial. Lancet Diabetes Endocrinol 2017;5:355-66.

78. DeVries JH, Bain SC, Rodbard HW, Seufert J, D’Alessio D, Thomsen AB, et al. Sequential intensification of metformin treatment in type 2 diabetes with liraglutide followed by randomized addition of basal insulin prompted by A1C targets.
Diabetes Care 2012;35:1446-54.

79. Aroda VR, Bailey TS, Cariou B, Kumar S, Leiter LA, Raskin P, et al. Effect of adding insulin degludec to treatment in patients with type 2 diabetes inadequately controlled with metformin and liraglutide: a double-blind randomized controlled trial (BEGIN: ADD TO GLP-1 Study). Diabetes Obes Metab 2016; 18:663-70.

80. Rosenstock J, Aronson R, Grunberger G, Hanefeld M, Piatti P, Serusclat $\mathrm{P}$, et al. Benefits of lixilan, a titratable fixed-ratio combination of insulin glargine plus lixisenatide, versus insulin glargine and lixisenatide monocomponents in type 2 diabetes inadequately controlled on oral agents: the LixiLan-O Randomized Trial. Diabetes Care 2016;39:2026-35.

81. Blonde L, Rosenstock J, Del Prato S, Henry R, Shehadeh N, Frias J, et al. Switching to iGlarLixi versus continuing daily or weekly GLP-1 RA in type 2 diabetes inadequately controlled by GLP-1 RA and oral antihyperglycemic therapy: the LixiLan-G Randomized Clinical Trial. Diabetes Care 2019;42: 2108-16.

82. Linjawi S, Bode BW, Chaykin LB, Courreges JP, Handelsman Y, Lehmann LM, et al. The efficacy of IDegLira (insulin degludec/liraglutide combination) in adults with type 2 diabetes inadequately controlled with a GLP-1 receptor agonist and oral therapy: DUAL III Randomized Clinical Trial. Diabetes Ther 2017;8:101-14.

83. Buse JB, Bergenstal RM, Glass LC, Heilmann CR, Lewis MS, Kwan AY, et al. Use of twice-daily exenatide in basal insulintreated patients with type 2 diabetes: a randomized, controlled trial. Ann Intern Med 2011;154:103-12.

84. Seino Y, Min KW, Niemoeller E, Takami A; EFC10887 GETGOAL-L Asia Study Investigators. Randomized, double-blind, placebo-controlled trial of the once-daily GLP-1 receptor agonist lixisenatide in Asian patients with type 2 diabetes insufficiently controlled on basal insulin with or without a sulfonylurea (GetGoal-L-Asia). Diabetes Obes Metab 2012;14:910-7.

85. Riddle MC, Aronson R, Home P, Marre M, Niemoeller E, Miossec $\mathrm{P}$, et al. Adding once-daily lixisenatide for type 2 diabetes inadequately controlled by established basal insulin: a 24-week, randomized, placebo-controlled comparison (GetGoal-L). Diabetes Care 2013;36:2489-96.

86. Riddle MC, Forst T, Aronson R, Sauque-Reyna L, Souhami E, Silvestre L, et al. Adding once-daily lixisenatide for type 2 diabetes inadequately controlled with newly initiated and continuously titrated basal insulin glargine: a 24-week, randomized, placebo-controlled study (GetGoal-Duo 1). Diabetes Care 
2013;36:2497-503.

87. Yang W, Min K, Zhou Z, Li L, Xu X, Zhu D, et al. Efficacy and safety of lixisenatide in a predominantly Asian population with type 2 diabetes insufficiently controlled with basal insulin: the GetGoal-L-C randomized trial. Diabetes Obes Metab 2018;20:335-43.

88. Ahmann A, Rodbard HW, Rosenstock J, Lahtela JT, de Loredo L, Tornoe K, et al. Efficacy and safety of liraglutide versus placebo added to basal insulin analogues (with or without metformin) in patients with type 2 diabetes: a randomized, placebo-controlled trial. Diabetes Obes Metab 2015;17:1056-64.

89. Pozzilli P, Norwood P, Jodar E, Davies MJ, Ivanyi T, Jiang H, et al. Placebo-controlled, randomized trial of the addition of once-weekly glucagon-like peptide-1 receptor agonist dulaglutide to titrated daily insulin glargine in patients with type 2 diabetes (AWARD-9). Diabetes Obes Metab 2017;19:1024-31.

90. Rodbard HW, Lingvay I, Reed J, de la Rosa R, Rose L, Sugimoto D, et al. Semaglutide added to basal insulin in type 2 diabetes (SUSTAIN 5): a randomized, controlled trial. J Clin Endocrinol Metab 2018;103:2291-301.

91. Aroda VR, Rosenstock J, Wysham C, Unger J, Bellido D, Gonzalez-Galvez G, et al. Efficacy and safety of lixilan, a titratable fixed-ratio combination of insulin glargine plus lixisenatide in type 2 diabetes inadequately controlled on basal insulin and metformin: the LixiLan-L randomized trial. Diabetes Care 2016;39:1972-80.

92. Rosenstock J, Diamant M, Aroda VR, Silvestre L, Souhami E, Zhou T, et al. Efficacy and safety of lixilan, a titratable fixedratio combination of lixisenatide and insulin glargine, versus insulin glargine in type 2 diabetes inadequately controlled on metformin monotherapy: the lixilan proof-of-concept randomized trial. Diabetes Care 2016;39:1579-86.

93. Buse JB, Vilsboll T, Thurman J, Blevins TC, Langbakke IH, Bottcher SG, et al. Contribution of liraglutide in the fixed-ratio combination of insulin degludec and liraglutide (IDegLira). Diabetes Care 2014;37:2926-33.

94. Lingvay I, Perez Manghi F, Garcia-Hernandez P, Norwood P, Lehmann L, Tarp-Johansen MJ, et al. Effect of insulin glargine up-titration vs insulin degludec/liraglutide on glycated hemoglobin levels in patients with uncontrolled type 2 diabetes: the DUAL V Randomized Clinical Trial. JAMA 2016;315:898907.

95. Lankisch MR, Ferlinz KC, Leahy JL, Scherbaum WA; Orals Plus Apidra and LANTUS (OPAL) study group. Introducing a simplified approach to insulin therapy in type 2 diabetes: a comparison of two single-dose regimens of insulin glulisine plus insulin glargine and oral antidiabetic drugs. Diabetes Obes Metab 2008;10:1178-85.

96. Leahy JL. Insulin therapy in type 2 diabetes mellitus. Endocrinol Metab Clin North Am 2012;41:119-44.

97. Rodbard HW, Visco VE, Andersen H, Hiort LC, Shu DH. Treatment intensification with stepwise addition of prandial insulin aspart boluses compared with full basal-bolus therapy (FullSTEP Study): a randomised, treat-to-target clinical trial. Lancet Diabetes Endocrinol 2014;2:30-7.

98. Aschner P, Sethi B, Gomez-Peralta F, Landgraf W, Loizeau V, Dain MP, et al. Insulin glargine compared with premixed insulin for management of insulin-naïve type 2 diabetes patients uncontrolled on oral antidiabetic drugs: the open-label, randomized GALAPAGOS study. J Diabetes Complications 2015;29:838-45.

99. Owens DR, Luzio SD, Sert-Langeron C, Riddle MC. Effects of initiation and titration of a single pre-prandial dose of insulin glulisine while continuing titrated insulin glargine in type 2 diabetes: a 6-month 'proof-of-concept' study. Diabetes Obes Metab 2011;13:1020-7.

100. Zinman B, Wanner C, Lachin JM, Fitchett D, Bluhmki E, Hantel S, et al. Empagliflozin, cardiovascular outcomes, and mortality in type 2 diabetes. N Engl J Med 2015;373:2117-28.

101. Kaku K, Lee J, Mattheus M, Kaspers S, George J, Woerle HJ, et al. Empagliflozin and cardiovascular outcomes in asian patients with type 2 diabetes and established cardiovascular disease: results from EMPA-REG OUTCOME ${ }^{\circledR}$. Circ J 2017;81: 227-34.

102. Gerstein HC, Colhoun HM, Dagenais GR, Diaz R, Lakshmanan M, Pais P, et al. Dulaglutide and cardiovascular outcomes in type 2 diabetes (REWIND): a double-blind, randomised placebo-controlled trial. Lancet 2019;394:121-30.

103. Marso SP, Daniels GH, Brown-Frandsen K, Kristensen P, Mann JF, Nauck MA, et al. Liraglutide and cardiovascular outcomes in type 2 diabetes. N Engl J Med 2016;375:311-22.

104. Marso SP, Bain SC, Consoli A, Eliaschewitz FG, Jodar E, Leiter LA, et al. Semaglutide and cardiovascular outcomes in patients with type 2 diabetes. N Engl J Med 2016;375:1834-44.

105. Wiviott SD, Raz I, Bonaca MP, Mosenzon O, Kato ET, Cahn A, et al. Dapagliflozin and cardiovascular outcomes in type 2 diabetes. N Engl J Med 2019;380:347-57.

106. Packer M, Anker SD, Butler J, Filippatos G, Pocock SJ, Carson $\mathrm{P}$, et al. Cardiovascular and renal outcomes with empagliflozin in heart failure. N Engl J Med 2020;383:1413-24. 
107. Cannon CP, Pratley R, Dagogo-Jack S, Mancuso J, Huyck S, Masiukiewicz U, et al. Cardiovascular outcomes with ertugliflozin in type 2 diabetes. N Engl J Med 2020;383:1425-35.

108. Wanner Ch, Inzucchi SE, Zinman B. Empagliflozin and progression of kidney disease in type 2 diabetes. $\mathrm{N}$ Engl J Med 2016;375:1801-2.

109. Heerspink HJ, Stefansson BV, Correa-Rotter R, Chertow GM, Greene T, Hou FF, et al. Dapagliflozin in patients with chronic kidney disease. N Engl J Med 2020;383:1436-46.

110. Levin A, Stevens PE, Bilous RW, Coresh J, De Francisco AL, De Jong PE, et al. KDIGO 2012 clinical practice guideline for the evaluation and management of chronic kidney disease. Kidney Int Suppl 2013;3:1-150.

111. Kasiske BL, Lakatua JD, Ma JZ, Louis TA. A meta-analysis of the effects of dietary protein restriction on the rate of decline in renal function. Am J Kidney Dis 1998;31:954-61.

112. Wheeler ML, Dunbar SA, Jaacks LM, Karmally W, Mayer-Davis EJ, Wylie-Rosett J, et al. Macronutrients, food groups, and eating patterns in the management of diabetes: a systematic review of the literature, 2010. Diabetes Care 2012;35:434-45.

113. Lewis EJ, Hunsicker LG, Bain RP, Rohde RD. The effect of angiotensin-converting-enzyme inhibition on diabetic nephropathy. The Collaborative Study Group. N Engl J Med 1993;329: 1456-62.

114. Brenner BM, Cooper ME, de Zeeuw D, Keane WF, Mitch WE, Parving $\mathrm{HH}$, et al. Effects of losartan on renal and cardiovascular outcomes in patients with type 2 diabetes and nephropathy. N Engl J Med 2001;345:861-9.

115. Heart Outcomes Prevention Evaluation Study Investigators. Effects of ramipril on cardiovascular and microvascular outcomes in people with diabetes mellitus: results of the HOPE study and MICRO-HOPE substudy. Lancet 2000;355:253-9.

116. Mauer M, Zinman B, Gardiner R, Suissa S, Sinaiko A, Strand $\mathrm{T}$, et al. Renal and retinal effects of enalapril and losartan in type 1 diabetes. N Engl J Med 2009;361:40-51.

117. Wanner C, Inzucchi SE, Lachin JM, Fitchett D, von Eynatten M, Mattheus M, et al. Empagliflozin and progression of kidney disease in type 2 diabetes. N Engl J Med 2016;375:323-34.

118. Diabetes Canada Clinical Practice Guidelines Expert Committee, Punthakee Z, Goldenberg R, Katz P. Definition, classification and diagnosis of diabetes, prediabetes and metabolic syndrome. Can J Diabetes 2018;42 Suppl 1:S10-5.

119. Saudek CD, Herman WH, Sacks DB, Bergenstal RM, Edelman D, Davidson MB. A new look at screening and diagnosing diabetes mellitus. J Clin Endocrinol Metab 2008;93:2447-
53.

120. Pop-Busui R, Low PA, Waberski BH, Martin CL, Albers JW, Feldman EL, et al. Effects of prior intensive insulin therapy on cardiac autonomic nervous system function in type 1 diabetes mellitus: the Diabetes Control and Complications Trial/Epidemiology of Diabetes Interventions and Complications study (DCCT/EDIC). Circulation 2009;119:2886-93.

121. Waldfogel JM, Nesbit SA, Dy SM, Sharma R, Zhang A, Wilson LM, et al. Pharmacotherapy for diabetic peripheral neuropathy pain and quality of life: a systematic review. Neurology 2017;88:1958-67.

122. Finnerup NB, Attal N, Haroutounian S, McNicol E, Baron R, Dworkin RH, et al. Pharmacotherapy for neuropathic pain in adults: a systematic review and meta-analysis. Lancet Neurol 2015;14:162-73.

123. Boulton AJ, Armstrong DG, Albert SF, Frykberg RG, Hellman R, Kirkman MS, et al. Comprehensive foot examination and risk assessment: a report of the task force of the foot care interest group of the American Diabetes Association, with endorsement by the American Association of Clinical Endocrinologists. Diabetes Care 2008;31:1679-85.

124. Hingorani A, LaMuraglia GM, Henke P, Meissner MH, Loretz L, Zinszer KM, et al. The management of diabetic foot: a clinical practice guideline by the Society for Vascular Surgery in collaboration with the American Podiatric Medical Association and the Society for Vascular Medicine. J Vasc Surg 2016; 63(2 Suppl):3S-21S.

125. The effect of intensive diabetes treatment on the progression of diabetic retinopathy in insulin-dependent diabetes mellitus: the diabetes control and complications trial. Arch Ophthalmol 1995;113:36-51.

126. Diabetes Control and Complications Trial Research Group. Effect of pregnancy on microvascular complications in the diabetes control and complications trial. The Diabetes Control and Complications Trial Research Group. Diabetes Care 2000; 23:1084-91.

127. Chew EY, Klein ML, Murphy RP, Remaley NA, Ferris FL 3rd. Effects of aspirin on vitreous/preretinal hemorrhage in patients with diabetes mellitus: Early Treatment Diabetic Retinopathy Study report no. 20. Arch Ophthalmol 1995;113:525.

128. The Diabetic Retinopathy Study Research Group. Preliminary report on effects of photocoagulation therapy. Am J Ophthalmol 1976;81:383-96.

129. Chalasani N, Younossi Z, Lavine JE, Charlton M, Cusi K, Ri- 
nella $\mathrm{M}$, et al. The diagnosis and management of nonalcoholic fatty liver disease: practice guidance from the American Association for the Study of Liver Diseases. Hepatology 2018;67: 328-57.

130. Koutoukidis DA, Astbury NM, Tudor KE, Morris E, Henry JA, Noreik M, et al. Association of weight loss interventions with changes in biomarkers of nonalcoholic fatty liver disease: a systematic review and meta-analysis. JAMA Intern Med 2019;179:1262-71.

131. Musso G, Cassader M, Paschetta E, Gambino R. Thiazolidinediones and advanced liver fibrosis in nonalcoholic steatohepatitis: a meta-analysis. JAMA Intern Med 2017;177:633-40.

132. Armstrong MJ, Gaunt P, Aithal GP, Barton D, Hull D, Parker $\mathrm{R}$, et al. Liraglutide safety and efficacy in patients with non-alcoholic steatohepatitis (LEAN): a multicentre, double-blind, randomised, placebo-controlled phase 2 study. Lancet 2016; 387:679-90.

133. Tang W, Xu Q, Hong T, Tong G, Feng W, Shen S, et al. Comparative efficacy of anti-diabetic agents on nonalcoholic fatty liver disease in patients with type 2 diabetes mellitus: a systematic review and meta-analysis of randomized and nonrandomized studies. Diabetes Metab Res Rev 2016;32:200-16.

134. Battelino T, Danne T, Bergenstal RM, Amiel SA, Beck R, Biester $\mathrm{T}$, et al. Clinical targets for continuous glucose monitoring data interpretation: recommendations from the International Consensus on Time in Range. Diabetes Care 2019;42:1593-603.

135. Heinemann L, Freckmann G, Ehrmann D, Faber-Heinemann G, Guerra S, Waldenmaier D, et al. Real-time continuous glucose monitoring in adults with type 1 diabetes and impaired hypoglycaemia awareness or severe hypoglycaemia treated with multiple daily insulin injections (HypoDE): a multicentre, randomised controlled trial. Lancet 2018;391:1367-77.

136. Battelino T, Phillip M, Bratina N, Nimri R, Oskarsson P, Bolinder J. Effect of continuous glucose monitoring on hypoglycemia in type 1 diabetes. Diabetes Care 2011;34:795-800.

137. Seyed Ahmadi S, Westman K, Pivodic A, Olafsdottir AF, Dahlqvist S, Hirsch IB, et al. The association between HbAlc and time in hypoglycemia during CGM and self-monitoring of blood glucose in people with type 1 diabetes and multiple daily insulin injections: a randomized clinical trial (GOLD-4). Diabetes Care 2020;43:2017-24.

138. Beck RW, Riddlesworth TD, Ruedy K, Ahmann A, Haller S, Kruger D, et al. Continuous glucose monitoring versus usual care in patients with type 2 diabetes receiving multiple daily insulin injections: a randomized trial. Ann Intern Med 2017; 167:365-74.

139. Vigersky RA, Fonda SJ, Chellappa M, Walker MS, Ehrhardt NM. Short- and long-term effects of real-time continuous glucose monitoring in patients with type 2 diabetes. Diabetes Care 2012;35:32-8.

140. Feig DS, Donovan LE, Corcoy R, Murphy KE, Amiel SA, Hunt $\mathrm{KF}$, et al. Continuous glucose monitoring in pregnant women with type 1 diabetes (CONCEPTT): a multicentre international randomised controlled trial. Lancet 2017;390:2347-59.

141. Yeh HC, Brown TT, Maruthur N, Ranasinghe P, Berger Z, Suh YD, et al. Comparative effectiveness and safety of methods of insulin delivery and glucose monitoring for diabetes mellitus: a systematic review and meta-analysis. Ann Intern Med 2012; 157:336-47.

142. Forlenza GP, Li Z, Buckingham BA, Pinsker JE, Cengiz E, Wadwa RP, et al. Predictive low-glucose suspend reduces hypoglycemia in adults, adolescents, and children with type 1 diabetes in an at-home randomized crossover study: results of the PROLOG trial. Diabetes Care 2018;41:2155-61.

143. Reznik Y, Cohen O, Aronson R, Conget I, Runzis S, Castaneda $\mathrm{J}$, et al. Insulin pump treatment compared with multiple daily injections for treatment of type 2 diabetes (OpT2mise): a randomised open-label controlled trial. Lancet 2014;384:1265-72.

144. Powers AC, Aronoff DM, Eckel RH. COVID-19 vaccine prioritisation for type 1 and type 2 diabetes. Lancet Diabetes Endocrinol 2021;9:140-1.

145. Korean Diabetes Association: Diabetes fact sheet in Korea. Available from: www.diabetes.or.kr (cited 2021 Jul 16). 